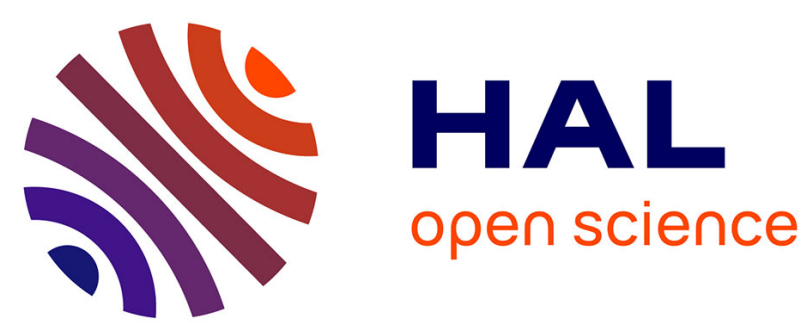

\title{
Organophilic bentonites obtained by microwave heating as adsorbents for anionic dyes
}

Deoclecio F Brito, Edson da Silva Filho, Maria Gardennia Fonseca, Maguy

Jaber

\section{- To cite this version:}

Deoclecio F Brito, Edson da Silva Filho, Maria Gardennia Fonseca, Maguy Jaber. Organophilic bentonites obtained by microwave heating as adsorbents for anionic dyes. Journal of Environmental Chemical Engineering, 2018, 6 (6), pp.7080-7090. 10.1016/j.jece.2018.11.006 . hal-01953608

\section{HAL Id: hal-01953608 https://hal.sorbonne-universite.fr/hal-01953608}

Submitted on 13 Dec 2018

HAL is a multi-disciplinary open access archive for the deposit and dissemination of scientific research documents, whether they are published or not. The documents may come from teaching and research institutions in France or abroad, or from public or private research centers.
L'archive ouverte pluridisciplinaire HAL, est destinée au dépôt et à la diffusion de documents scientifiques de niveau recherche, publiés ou non, émanant des établissements d'enseignement et de recherche français ou étrangers, des laboratoires publics ou privés. 


\title{
Organophilic bentonites obtained by microwave heating as adsorbents for anionic dyes
}

\author{
Deoclecio F. Brito ${ }^{1,2}$, Edson C. da Silva Filho ${ }^{3}$, Maria G. Fonseca ${ }^{2 *}$, Maguy Jaber ${ }^{4}$ \\ ${ }^{1}$ Universidade Estadual da Paraíba, Departamento de Química, 584295, Campina \\ Grande, Paraíba, Brazil.
}

${ }^{2}$ Universidade Federal da Paraíba, Núcleo de Pesquisa e Extensão - Laboratório de Combustíveis e Materiais (NPE - LACOM), 58051970, João Pessoa, Paraíba, Brazil.

${ }^{3}$ Laboratório Interdisciplinar de Materiais Avançados (LIMAV), Centro de Tecnologia, UFPI, 64064-260, Teresina, Piaui, Brazil.

${ }^{4}$ Sorbonne Université, Laboratoire d'Archéologie Moléculaire et Structurale, CNRS UMR 8220, UPMC - Tour 23, 3ème étage, couloir 23-33, BP 225, 4 place Jussieu, 75005 Paris, France.

*Corresponding author: mgardennia@quimica.ufpb.br

Phone/fax +55(83) 3216-7441 


\section{Abstract}

Organobentonites were prepared using three cationic surfactants tetradecyl- (C14), hexadecyl- (C16) and octadecyltrimethylammonium (C18) bromides in the proportions of $100 \%$ and $200 \%$ of the cationic exchange capacity (CEC) at $323 \mathrm{~K}$ under microwave irradiation for $5 \mathrm{~min}$. The XRD patterns indicated the formation of intercalated hybrids with $\mathrm{d}$ values in the range 1.83 to $2.00 \mathrm{~nm}$. CHN elemental analysis showed better organofunctionalization of the clay matrix for the organobentonites obtained with $200 \%$ of the CEC and longer organic alkyl chains and agreed with thermogravimetric analysis. Infrared spectroscopy suggested the presence of the organic moieties on organobentonites, showing typical absorptions of $\mathrm{CH}_{2}$ and $\mathrm{CH}_{3}$ groups. The solids were applied for Remazol blue RN dye removal from a single and synthetic effluent sample. The influences of the $\mathrm{pH}$, adsorbent dosage, contact time and initial dye concentration were systematically investigated. The data were fitted to different kinetic and equilibrium models. All of the adsorption processes were adjusted to pseudo-second order and Langmuir models. The organobentonites showed good performance in dye removal at a $\mathrm{pH}$ of 2 for the solids obtained with $100 \%$ of the CEC, and the dye removal was independent of the $\mathrm{pH}$ for the other solids, which is in agreement with the zeta potential measurements. The optimal reaction time was 60 min, except for Bent-C16$200 \%$. The best dye removal efficiency $\left(100 \%-211 \mathrm{mg} \mathrm{g}^{-1}\right)$ for the Bent-C14-200\% sample with $500 \mathrm{mg} / \mathrm{L}$ of dye concentration.

Keywords Bentonite; organoclay; anionic dyes; adsorption 


\section{Introduction}

Dyestuffs are important pollutants and many of them are non-biodegradable, being widely used in some industries, such as textiles, leather, pharmaceuticals, paper, among others (Tangaraj et al., 2017, Kausar et al., 2018). Reactive anionic dyes, such as Remazol blue RN, disodium 1-amino-9,10-dioxo-4-[3-(2sulfonatooxyethylsulfonyl)anthracene-2-sulfonate, have anthraquinone as a chromophore. They are toxic and recalcitrant dyes, and they represent approximately $30 \%$ of the paint production in the world. Their environmental importance is that 10 to $50 \%$ of them can remain in solution after the dyeing process (Janaki et al. 2012). The discharge of the effluents containing dyes in aquatic environments damage the ecological balance and living organisms by the influence of the chemical groups present in the dye structure (Torgut et al., 2017). However, the major environmental concern due the presence of dye in aquatic medium is the absorption and reflection of sunlight, which interfere in the growth of the bacteria to levels insufficient to biologically degradation of the impurities in the water resulting in ecological imbalance (Unuabonah et al., 2008).

Several processes for the removal and/or treatment of dyes have been proposed, such as filtration, chemical treatment, advanced oxidative processes, biodegradation, membrane separation, and electrochemical methods (Gupta et al., 2009; Rehman et al., 2014). However, adsorption is the most widely used method, since adsorption is easy to operate and has the possibility of selectivity as well as the reuse of the adsorbent (Huang et al., 2014). Some adsorbents often present high costs of production and regeneration (for example, carbon nanotubes, metal-organic frameworks (MOFs) and ion exchange membranes), which may make them economically unfeasible. Therefore, natural adsorbents with a low cost, a large surface area and/or active sites on the surface 
have been extensively explored (Ngulube et al., 2017). Bentonite is a natural mineral composed of at least $50 \%$ smectite, and more precisely montmorillonite, a 2:1 phyllosilicate (Brigatti et al., 2013), and meet all of these requirements. Montmorillonite is constituted of an aluminum octahedron sheet sandwiched between two silicon tetrahedron sheets. Isomorphic substitution of $\mathrm{Al}^{3+}$ by $\mathrm{Mg}^{2+}$ in the octahedral sheet gives an overall negative charge, which is counterbalanced by cations located in the interlayer space (Bergaya et al., 2011; Jaber, et.al., 2014). Furthermore, bentonites are abundant, easy to handle, biocompatible, and non-toxic (Zhu et al. 2015) and presents other properties as thermal stability, nanoscale porous structure, appropriate surface morphology, chemical stability (Fatimah et al., 2011; Hassane et al., 2015; Sahin et al., 2015; Elfadl et al., 2017).

Due to their negatively charged surface, bentonites have a low affinity for anionic species like reactive dyes such as Remazol textile dyes (Silva, et al., 2012; Pereira et al., 2017); therefore the use of organobentonites is an alternative way, because the organic cations inserted in the clay minerals give better affinity for organic species dissolved in solutions (Teppen et al., 2007). The net charge of the solid is changed and made more easily the interaction with negatively charged species (Ma et al., 2011; Tunç et al., 2012). Organobentonites have been applied for dye removal from aqueous solutions (Ma et al., 2011; Fan et al., 2014; Yan et al., 2015; Anirudhan et al., 2015; Tangaraj et al., 2017; Wang et al., 2017).

The synthesis of organobentonites usually involves an ion exchange reaction between organic alkyl quaternary ammonium salts and the interlayer cations (Paiva et al., 2008; Chiu et al., 2014). Generally, ammonium cations with long linear alkyl chains or alkyl phosphonium surfactants could be intercalated into the silicate interlayer gallery to enlarge the basal spacing (Bergaya et al., 2011). Synthesis of organoclays has been 
well-described in aqueous solutions at room temperature or at moderate temperatures such as $40-50^{\circ} \mathrm{C}$ (Paiva et al 2008) over a range of times (hours or days).

The hydrophobic nature of the organobentonites results in their use for the sorption of organopollutants. Lagaly et al., (1970, 1971) proposed that organoclays prepared with alkylammonium cations present different arrangements of the organic moieties in the interlayer spacing such as a lateral monolayer, a bilayer parallel to the silicate layers, paraffin-like monomolecular or paraffin-like bimolecular arrangements. More recently, some studies indicated that the properties of the organically-modified bentonites depend on their cation exchange capacity (CEC) and the surfactant structure, that is, the nature of the head group, number of chains per head group and chain length (Heinz et al., 2005; 2007). These studies based on experimental and molecular simulations showed that in low charged montmorillonite, the formation of partially and densely packed alkyl layers can be observed. Thus, when alkylammonium surfactants with $\mathrm{C}_{10^{-}} \mathrm{C}_{22}$ chains were used, a partial formation of an alkyl bilayer was observed for $\mathrm{C}_{10}$, a low interlayer density of the alkyl bilayer was observed for $\mathrm{C}_{14}$ and a densely packed bilayer was observed for a $\mathrm{C}_{18}$ chain length. The formation of a partial alkyltrilayer occurred for a chain length of $\mathrm{C}_{22}$ (Fu and Heinz, 2010).

In the present study, organobentonites were prepared by the reaction between ammonium salts and bentonites under microwave heating. Currently, microwave chemistry has received remarkable attention, owing to its powerful thermal effect that helps in the completion of the reactions in the shortest time by means of rapid and uniform heating, because the use of microwave radiation targets mainly to carbon-based material with good microwave absorbency (Kar et al., 2016). When the carbon material is exposed to microwave radiation, dipole rotation in atomic scale is occurred up to million times per second within the material. As a result, heat energy is rapidly 
generated from the frictions between the atoms and molecules within the material which subsequently leads to fast heating of the material (Lam et. al., 2016; Liew et al., 2018). Some studies described the use of the microwave assisted reactions for synthesis of modified bentonites (Farias et al., 2015; Kar et al., 2016; Fabryanty et al., 2017; Mishra et al., 2017).

Therefore, the aim of the present work was to prepare organobentonites by using three surfactants (tetradecyltrimethylammonium bromide (C14), hexadecyltrimethylammonium bromide (C16) and octadecyltrimethylammonium bromide $(\mathrm{C} 18)$ ) by microwave heating. The prepared bentonites were applied to Remazol blue RN removal, while evaluating different experimental conditions. The influence of the organic chain size in the chemical structure of the adsorbents was investigated. The efficiencies of the solids were also tested for a synthetic effluent, which was composed of three different anionic dyes (Remazol blue RN, Remazol red RB and Remazol yellow GR) in the presence of inorganic salts.

\section{Experimental}

\subsection{Materials}

A sodium bentonite sample was obtained from the Bentonise Bentonita Company, Brazil. The sample was ground and sieved to a particle size below $74 \mu \mathrm{m}$. The CEC was $88 \mathrm{cmol}(+) / \mathrm{kg}$, as measured by the ammonium-exchange method (Dohrmann, 2006). The chemical composition of the bentonite after reaction with a $\mathrm{HF} / \mathrm{HNO}_{3}$ mixture was obtained by atomic absorption spectroscopy. Bentonite has the following constituents $\mathrm{SiO}_{2}(52.98 \%), \mathrm{Al}_{2} \mathrm{O}_{3}$ (18.35\%), $\mathrm{Fe}_{2} \mathrm{O}_{3}(3.96 \%), \mathrm{Na}_{2} \mathrm{O}$ (2.56\%), 
$\mathrm{MgO}(2.47 \%), \mathrm{TiO}_{2}(0.18 \%), \mathrm{K}_{2} \mathrm{O}(0.22 \%)$ and $\mathrm{CaO}(0.01 \%)$. Heat loss at $1223 \mathrm{~K}$ was $18.6 \%$.

Three cationic surfactants C14, C16 and C18 (99\% of purity) were supplied from Sigma-Aldrich and used as received.

Remazol Blue RN $\left(\mathrm{C}_{22} \mathrm{H}_{16} \mathrm{~N}_{2} \mathrm{Na}_{2} \mathrm{O}_{11} \mathrm{~S}_{3}\right)$, remazol red GR (tetrasodium 4-[[4chloro-6-(4-sulfonatoanilino)-1,3,5-triazin-2-yl]amino]-5-oxido7-sulfo-6-[

$\left.\mathrm{C}_{24} \mathrm{H}_{18} \mathrm{ClN}_{7} \mathrm{Na}_{4} \mathrm{O}_{15} \mathrm{~S}_{5}\right)$ and remazol yellow GR (disodium 4-(4-((2-methoxy-5-methyl-4-

((2-sulfonatoethyl) sulfonyl)phenyl) diazenyl) -3-methyl-5-oxo-4,5-dihydro-1Hpyrazol-1-yl)benzenesulfonate) were supplied by DyStar Company, Brazil.

For synthetic effluent the following salts were used as received. $\mathrm{Na}_{3} \mathrm{PO}_{4}$ (Synth, 99\%), $\mathrm{Na}_{2} \mathrm{CO}_{3}$ (Vetec, 99\%), $\mathrm{NaCH}_{3} \mathrm{COO}$ (Vetec, 99\%), $\mathrm{NH}_{4} \mathrm{Cl}$ (Fmaia, 99.5\%), $\mathrm{NaCl}$ (Vetec, 99\%), $\mathrm{KNO}_{3}$ (Sigma-Aldrich, 99\%) and $\mathrm{Na}_{2} \mathrm{SO}_{4}$ (Moderna, 99\%).

\subsection{Preparation of the organobentonites}

Organobentonites were prepared as follows: $4.0 \mathrm{~g}$ of the clay was transferred to a Teflon vessel reactor and suspended in $100 \mathrm{~mL}$ of the surfactant solution. The amount of the surfactant in solution was equivalent to 100 and $200 \%$ of the CEC of the clay. The amount of each surfactant was above the critical micelle concentration, which had values of 0.0033 (C14), 0.0009 (C16) (Acisli et al., 2017) and 0.00032 (C18) (Mellott et al., 2004). The mixture was heated in a microwave reactor for $5 \mathrm{~min}$ at $323 \mathrm{~K}$ in an ISTEC MW reactor model RMW-1, Brazil, with potency of $1100 \mathrm{~W}$ and $2.45 \mathrm{GHz}$. The final suspension was centrifuged, and the solid was washed until no bromide ions were detected by $0.1 \mathrm{~mol} \mathrm{~L}^{-1}$ silver nitrate solution. The solid was dried at $333 \mathrm{~K}$ for $48 \mathrm{~h}$, 
pulverized in an agate mortar and sieved to 200 mesh. All experiments were conducted in triplicate, and the initial and final $\mathrm{pH}$ were monitored; however, $\mathrm{pH}$ variations were not observed.

\subsection{Characterization}

X-ray diffraction (XRD) patterns were obtained using a Shimadzu XD3A model diffractometer, with $\mathrm{Cu} K \alpha$ radiation $(\lambda=0.15406 \mathrm{~nm})$, operating at $40 \mathrm{kV}$ and $30 \mathrm{~mA}$. The diffractions patterns were performed between $1.5-70^{\circ}(2 \theta)$ with scanning rate of $0.05 \mathrm{deg} \mathrm{min}^{-1}$ at room temperature. Fourier transform infrared spectroscopy (FTIR) was performed in a Bomem MB-series FT spectrometer. The samples were prepared at $\mathrm{KBr}$ pellets with a concentration of $2 \%$. The FTIR spectra $\left(4000-400 \mathrm{~cm}^{-1}\right)$ were recorded with resolution of $4 \mathrm{~cm}^{-1}$ and 32 accumulations. TG measurements was carried out by a TG I/1600 HT simultaneous thermal analyzer in a argon flow of $50 \mathrm{~mL} \mathrm{~min}^{-1}$ with $10 \mathrm{mg}$ of samples and a heating rate of $283 \mathrm{~K} \mathrm{~min}^{-1}$ until $1273 \mathrm{~K}$. The degree of organofunctionalization was determined based on $\mathrm{CHN}$ elemental analysis, which was

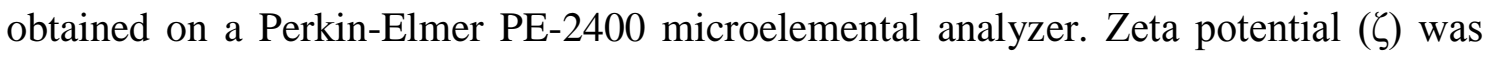
monitored on a Zetasizer Nano Zs -Malvern Instruments for isoelectric titration through $\mathrm{pH}$ titration. The $\mathrm{pH}$ of solutions was adjusted with $0.100 \mathrm{~mol} \mathrm{~L}^{-1} \mathrm{NaOH}$ or $0.500 \mathrm{~mol}$ $\mathrm{L}^{-1} \mathrm{HNO}_{3}$.

\subsection{Adsorption experiments}

Batch experiments were employed to determine the adsorption capacities of the dyes on the modified bentonites. Adsorbent $(0.05 \mathrm{~g})$ was added to $20 \mathrm{~mL}$ of $500 \mathrm{mg} \mathrm{L}^{-1}$ 
dye solution in an Erlenmeyer flask, and the samples were then shaken at $303 \mathrm{~K}$ for 24 h. The initial solution $\mathrm{pH}$ was adjusted to be in a range of 2 to 7 with $0.1 \mathrm{~mol} \mathrm{~L}^{-1} \mathrm{HNO}_{3}$ or $\mathrm{NaOH}$. After reaching adsorption equilibrium, the mixtures were centrifuged at 5000 rpm, and the solution was collected in a syringe. The dye was quantified by a UV-VIS spectrophotometer (Shimadzu UV-2550) at $592 \mathrm{~nm}$.

The amount of dye removed on the adsorbents was calculated from Equation 1:

$$
q=\frac{\left(C_{i}-C_{e}\right) \cdot V}{m}
$$

where $\mathrm{q}$ is the adsorption capacity $\left(\mathrm{mg} \mathrm{g}^{-1}\right) ; \mathrm{C}_{\mathrm{i}}$ and $\mathrm{C}_{\mathrm{e}}$ are the initial and equilibrium dye concentrations $\left(\mathrm{mg} \mathrm{L}^{-1}\right)$, respectively; $\mathrm{m}(\mathrm{g})$ is the mass of adsorbent; and $\mathrm{V}(\mathrm{L})$ is the dye solution volume.

The influence of the adsorbent dosage was monitored at a fixed $\mathrm{pH}$ using masses of $25,50,75$ and $100 \mathrm{mg}$, which reacted with $20 \mathrm{~mL}$ of $500 \mathrm{mg} \mathrm{L}^{-1}$ dye solution for 24 h. Afterwards, the same procedure was followed to separate the solid and to quantify the dye in aqueous solution.

Adsorption kinetics analysis was conducted with a $500 \mathrm{mg} \mathrm{L}^{-1}$ initial dye concentration at $303 \mathrm{~K}$ at the optimum $\mathrm{pH}$ between 10-240 min.

Equilibrium isotherms were obtained for initial dye concentrations varying from 100 to $1400 \mathrm{mg} \mathrm{L}^{-1}$ at the optimum $\mathrm{pH}$, adsorbent dosage and contact time.

\subsection{Kinetic and equilibrium models}


Kinetic equations pseudo-first order (Lagergren and Svenska, 1898), pseudosecond order (Ho and Mckay, 1999) and Elovich model (Elovich and Larinov, 1962) were applied to study the adsorption process as described the following equations 2-4:

pseudo-first order: $\ln \left(q_{e, \text { exp }}-q_{t}\right)=\ln q_{e, \text { cal }}-k_{1} t$

pseudo-second order: $\frac{t}{q_{t}}=\frac{1}{k_{2} q_{e, c a l}^{2}}+\frac{1}{q_{e, c a l}} t$

Elovich: $q_{t}=\frac{1}{\beta} \ln (\alpha \beta)+\frac{1}{\beta} \ln t$

Where $\mathrm{q}_{\mathrm{e}}$ and $\mathrm{q}_{\mathrm{t}} \mathrm{mg} \mathrm{g}^{-1}$ are the adsorption capacities at the equilibrium and in a time $\mathrm{t}(\mathrm{min})$ respectively.

In the Eq. $4 \alpha\left(\mathrm{mg} \mathrm{g}^{-1} \mathrm{~min}^{-1}\right)$ and $\beta\left(\mathrm{g} \mathrm{mg}^{-1}\right)$ are the initial adsorption rates and Elovich constant related to the extent of surface coverage and also to the activation energy involved in chemisorption, respectively.

The data of the equilibrium isotherms were fitted to Langmuir (Langmuir, 1916), Freundlich (Freundlich, 1906) and Temkin models (Temkin and Pyzhev, 1940), following the equations 5-7:

Langmuir: $\frac{C_{e}}{q_{e}}=\frac{1}{q_{\text {máx }} K_{L}}+\frac{C_{e}}{q_{\text {máx }}} \quad R_{L}=\frac{1}{1+K_{L} C_{e}}$

Freundlich: $\ln q_{e}=\ln K_{f}+\frac{1}{n_{f}} \ln C_{e}$

Temkin: $q_{e}=\frac{R T}{b_{T}} \ln A_{T}+\frac{R T}{b_{T}} \ln C_{e}$ 
Where $\mathrm{C}_{\mathrm{e}}\left(\mathrm{mg} \mathrm{L}^{-1}\right)$ is the dye equilibrium concentration, $\mathrm{q}_{\mathrm{e}}\left(\mathrm{mg} \mathrm{g}^{-1}\right)$ is the dye adsorbed amount on solid/liquid interface, $\mathrm{q}_{\max }\left(\mathrm{mg} \mathrm{g}^{-1}\right)$ is the maximum removal to form a monolayer of the dye on surface, $\mathrm{k}_{\mathrm{L}}\left(\mathrm{L} \mathrm{mg}^{-1}\right)$ is the Langmuir constant.

In the Freundlich model $\mathrm{K}_{\mathrm{F}}\left(\mathrm{mg} \cdot \mathrm{g}^{-1}\right)\left(\mathrm{mg} \cdot \mathrm{L}^{-1}\right)^{-1 / n}$ and $\mathrm{n}$ are the Freundlich constant and a factor which are related to capacity and intensity of the adsorption, respectively. For Temkin model, $b_{T}$ is the constant related to adsorption energy ( $\mathbf{J}$ $\left.\mathrm{mol}^{-1}\right)$, At $\left(\mathrm{L} \mathrm{mg}^{-1}\right)$ is the Temkin isotherm constant, $\mathrm{R}$ is the gas constant $(8.314 \mathrm{~J}$ $\mathrm{mol}^{-1} \mathrm{~K}$ ) and $\mathrm{T}$ is the temperature (K).

\subsection{Test with a simulated effluent solution}

A synthetic dye solution consisting of three anionic dyes (Figure SM1) at 33.3 $\mathrm{mg} \mathrm{L}^{-1}$ of each dye in the presence of each inorganic salt at $15 \mathrm{mg} \mathrm{L}^{-1}$ was prepared and used as the synthetic effluent (Thue et al. 2018).

The adsorption test was performed using $20 \mathrm{~mL}$ of the effluent solution, which reacted with $75 \mathrm{mg}$ of solid and the samples were then shaken at $303 \mathrm{~K}$ for $3 \mathrm{~h}$ at $\mathrm{pH}$ values of 2 and 6.4. The adsorption was monitored by UV-VIS spectrometry in the range of 190 to $900 \mathrm{~nm}$. The dye mixture showed maximum absorptions at 412, 540 and $609 \mathrm{~nm}$ associated with Remazol yellow GR, Remazol red RB and Remazol blue RN, respectively.

\subsection{Stability test}

The desorption experiments were conducted by suspending the dye-loaded adsorbent (50 $\mathrm{mg}$ of the solid previously exposed to $1000 \mathrm{mgL}^{-1}$ initial dye concentration) with $20 \mathrm{~mL}$ of $0.1 \mathrm{~mol} \mathrm{~L}^{-1} \mathrm{NaOH}$ or $0.1 \mathrm{~mol} \mathrm{~L}^{-1} \mathrm{HCl}$, ethanol (95\%), 
separately. The mixtures were shaken at $200 \mathrm{rpm}$ and $298 \mathrm{~K}$ for at least $12 \mathrm{~h}$. After desorption, the supernatant was centrifuged and the dye in solution was quantified as described in the subsection 2.2 .

\section{Results and discussion}

\subsection{XRD}

The XRD patterns of the pristine and organobentonites are depicted in Figure 1. The pure bentonite presented the characteristic peak of dioctahedral montmorillonite with reflections at $2 \theta$ values of $7^{\circ}(001)$ and $62^{\circ}(060)$ associated with a basal spacing of $1.2 \mathrm{~nm}$ and interplanar distance of $0.149 \mathrm{~nm}$ (Duane and Robert, 1997).

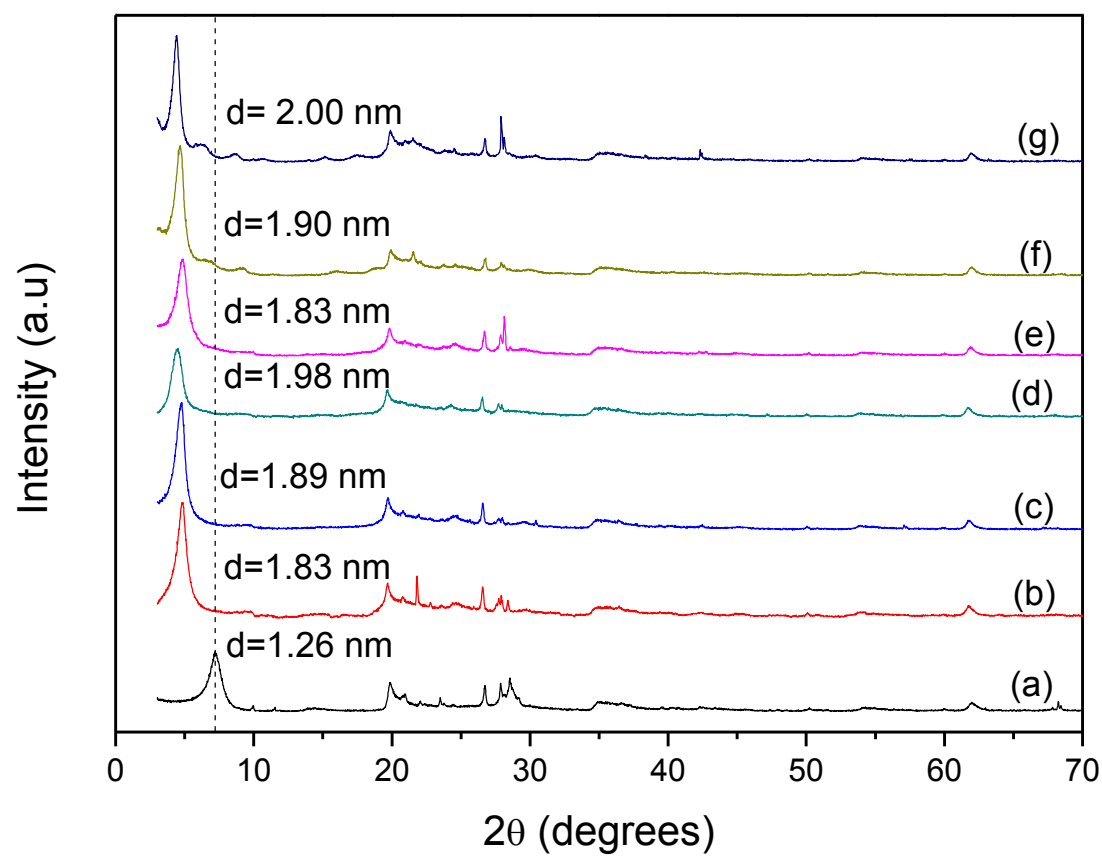

Figure 1. XRD patterns for (a) pristine bentonite and organo bentonites, (b) Bent-C14100\%, (c) Bent-C16-100\%, (d) Bent-C18-100\%, (e) Bent-C14-200\%, (f) Bent-C16$200 \%$ and (g) Bent-C18-200\%. 
For the organobentonites, the reflections in the 001 plan were changed for lower $2 \theta$ values (Figure 1i), reflecting an increase in the basal spacing values and the occurrence of the intercalation of the surfactants in the Mt. The values were $1.83,1.89$ and $1.98 \mathrm{~nm}$ for Bent-C14-100\%, Bent-C16-100\% and Bent-C18-100\%, respectively. For the samples Bent-C14-200\%, Bent-C16-200\% and Bent-C18-200\%, the distances were $1.83,1.90$ and $2.00 \mathrm{~nm}$, respectively (Figure 1ii). The increase in the basal spacing suggested the intercalation of the ammonium ions into the interlayer space of the montmorillonite. Higher values were observed for longer organic chain lengths, as reported in the literature for samples obtained by using conventional heating (Ma et al., 2011; Schampera et. al., 2016; Acisli et al., 2017). Increasing the amount of organic modifier (100 and $200 \%$ of the CEC) did not drastically alter the interlayer spacing. Although the basal spacing depends on the interlayer cations and their hydration (Lepoitevin et al., 2014), the obtained values were compared with ammonium-modified montmorillonites obtained by conventional heating (Table SM1).

The values of the basal spacings for the prepared organobentonites with $100 \%$ of the CEC were close to those obtained by Fu and Heinz (2010) using a montmorrillonite with $91 \mathrm{cmol}(+) / \mathrm{kg}$ of CEC, which was organo-modified with the same ammonium quaternary salts $\left(\mathrm{C}_{14}, \mathrm{C}_{16}\right.$ and $\left.\mathrm{C}_{18}\right)$. Based on more recent studies cited by Heinz (2011), the arrangements of the organic moieties were suggested based on the difference between the $\mathrm{d}(001)$ values and the layer thickness of Mt ( 0.97-1.0 $\mathrm{nm})$ (Bergaya et al., 2011). For example, for the solids modified with $\mathrm{C}_{18}$, the difference was $0.98 \mathrm{~nm}$, which corresponds to the arrangement of the surfactant ions in a bilayer parallel to plane of the layers (Figure 2). The obtained thicknesses of the intercalated surfactants were, therefore, $0.98 \mathrm{~nm}$, and this value is approximately double the thickness of the 
surfactant, which is known to be $0.51-0.67 \mathrm{~nm}$ for the hydrophilic head group from other studies, thus confirming a bilayer arrangement (Daoudi et al., 2013; Park et al., 2017; Taleb et al., 2018). Therefore, the obtained values were higher than $0.95 \mathrm{~nm}$ for all of the prepared organobentonites, indicating a bilayer arrangement of the alkyl ammonium cations with charged surfactant head groups disposed alternatively in the interlayer spacing of the montmorillonite. These present results are in agreement with other studies (Park et al., 2011; Daoudi et al., 2013; Sun et al., 2013; Tangaraj et al., 2017; Acisli et al., 2017).
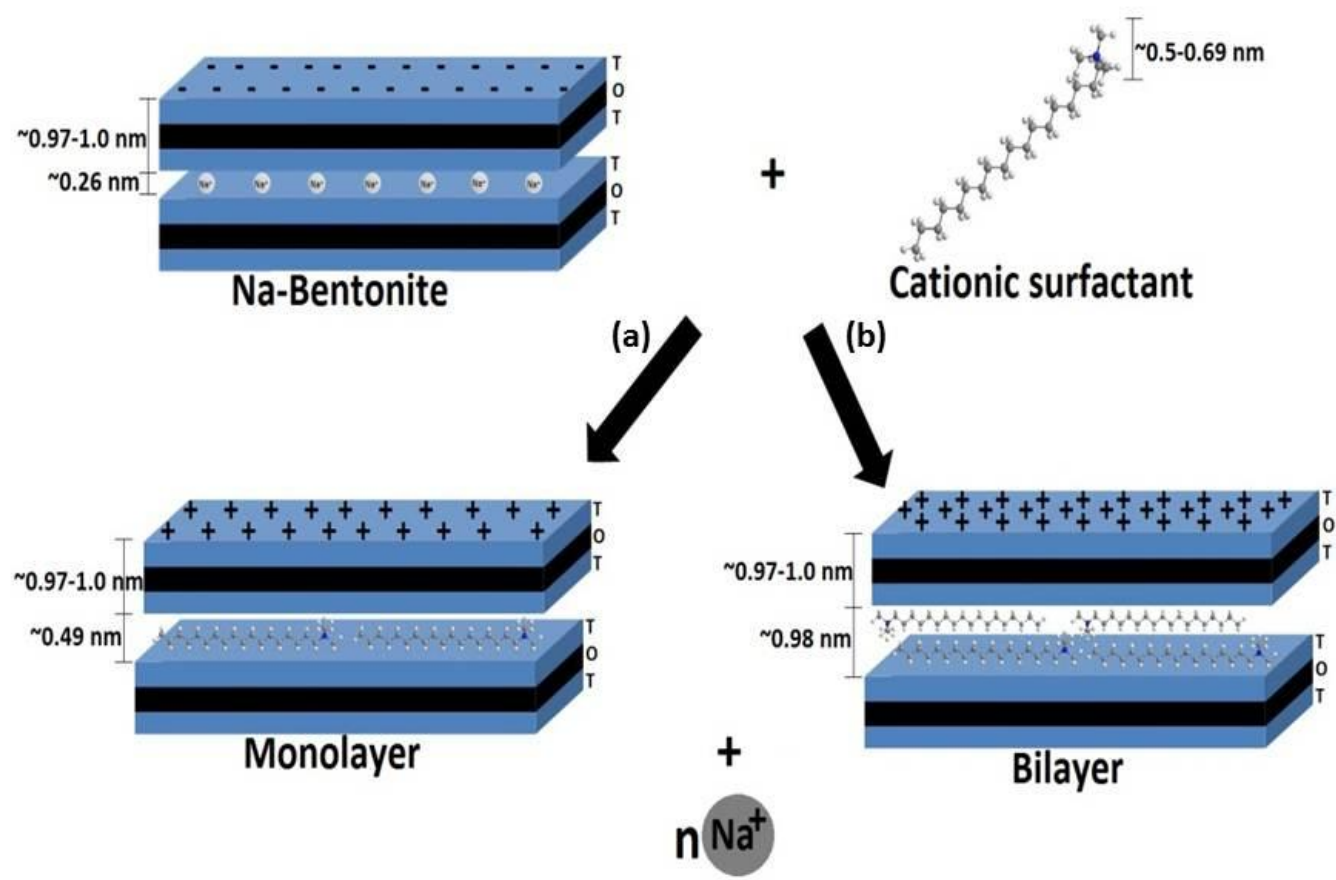

Figure 2. Illustration of the surfactant molecules in the interlayer spacing of montmorillonite in (a) monolayer and (b) bilayer arrangements.

\subsection{CHN elemental analysis}


The CHN elemental analysis results for the organobentonites obtained by microwave heating are presented in Table 1 . High values for the organic content were observed for solids obtained with longer organic chain lengths for both groups of modified bentonites, as indicated by the carbon percentages. These results agree with those of other works (Mizutani et al., 1995; Teppen and Aggarwal, 2007), where it was observed that the smectites are more selective for organic cations with higher chain length and with more ramified chains, where the variation in the hydration energy is a factor for the selectivity of the reaction.

Table 1. CHN elemental analysis for the organobentonites

\begin{tabular}{lccccc}
\hline Hybrid & \multicolumn{3}{c}{$\mathrm{C}$} & $\mathrm{H}$ & \multicolumn{2}{c}{$\mathrm{N}$} \\
\hline & $\%$ & $\mathrm{mmol} \mathrm{g}^{-1}$ & $\%$ & $\%$ & $\mathrm{mmol} \mathrm{g}^{-1}$ \\
Bent & 0.11 & 0.09 & 1.94 & - & - \\
Bent-C14-100\% & 15.64 & 13.03 & 3.57 & 1.08 & 0.77 \\
Bent-C16-100\% & 17.82 & 14.85 & 3.78 & 1.10 & 0.79 \\
Bent-C18-100\% & 19.15 & 15.96 & 4.12 & 1.15 & 0.82 \\
Bent-C14-200\% & 18.87 & 15.72 & 4.15 & 1.31 & 0.94 \\
Bent-C16-200\% & 24.74 & 20.62 & 5.20 & 1.50 & 1.07 \\
Bent-C18-200\% & 28.42 & 23.68 & 5.79 & 1.54 & 1.10 \\
\hline
\end{tabular}

The incorporation was better when the amount of surfactant used was $200 \%$ of the CEC. This fact can be indicative that the surfactant:bromide ion pair can be intercalated together, and therefore, ion exchange is not the only mechanism of interaction between 
the montmorillonite and ammonium salts. Similar results were observed for interaction with C16 (Sun et al., 2017; Ma et al., 2011) and C18 (Sahnoun et al., 2018).

Another aspect to be considered is that basal spacings were close for both groups of solids; this indicates that the solids obtained with $200 \%$ of the CEC have higher packaging than those prepared with $100 \%$ of the CEC.

\subsection{Infrared spectroscopy}

Infrared spectroscopy is useful to indicate the presence of organic moieties on the solids. Bentonite was mainly composed of sodium montmorillonite and typical absorptions bands of the inorganic sheets were observed. Infrared spectrum of pristine bentonite (Figure 3) presents a band at $3630 \mathrm{~cm}^{-1}$ assigned to $\mathrm{OH}$ structural stretching $\left(\mathrm{M}-\mathrm{OH}, \mathrm{M}^{\mathrm{n}+}=\mathrm{Al}^{3+}, \mathrm{Mg}^{2+}\right)$ and a broad band at $3433 \mathrm{~cm}^{-1}$ associated with the $\mathrm{OH}$ stretching of the adsorbed and interlayer water as well as SiOH (Madejová et al., 1998; Petit and Madejová, 2013). The band associated with water deformation is present at $1638 \mathrm{~cm}^{-1}$. The absorption related to silicate anions is observed at $1035 \mathrm{~cm}^{-1}$ due to $\mathrm{Si}-\mathrm{O}$ stretching. The bands observed at 914 and $840 \mathrm{~cm}^{-1}$ were assigned to Al-Al-OH and Al$\mathrm{Mg}-\mathrm{OH}$, respectively and suggested the partial $\mathrm{Al}^{3+}$ substitution by $\mathrm{Mg}^{2+}$ in the octahedral layer (Madejová et al., 1998). Other absorptions were observed at $631 \mathrm{~cm}^{-1}$ (M-O-Si; $\mathrm{M}=\mathrm{Al}, \mathrm{Mg}$ ), $522 \mathrm{~cm}^{-1}$ and $460 \mathrm{~cm}^{-1}$ (Si-O-Al and $\mathrm{Si}-\mathrm{O}-\mathrm{Mg}$, respectively) (Madejová et al., 1998; Petit and Madejová, 2013). 

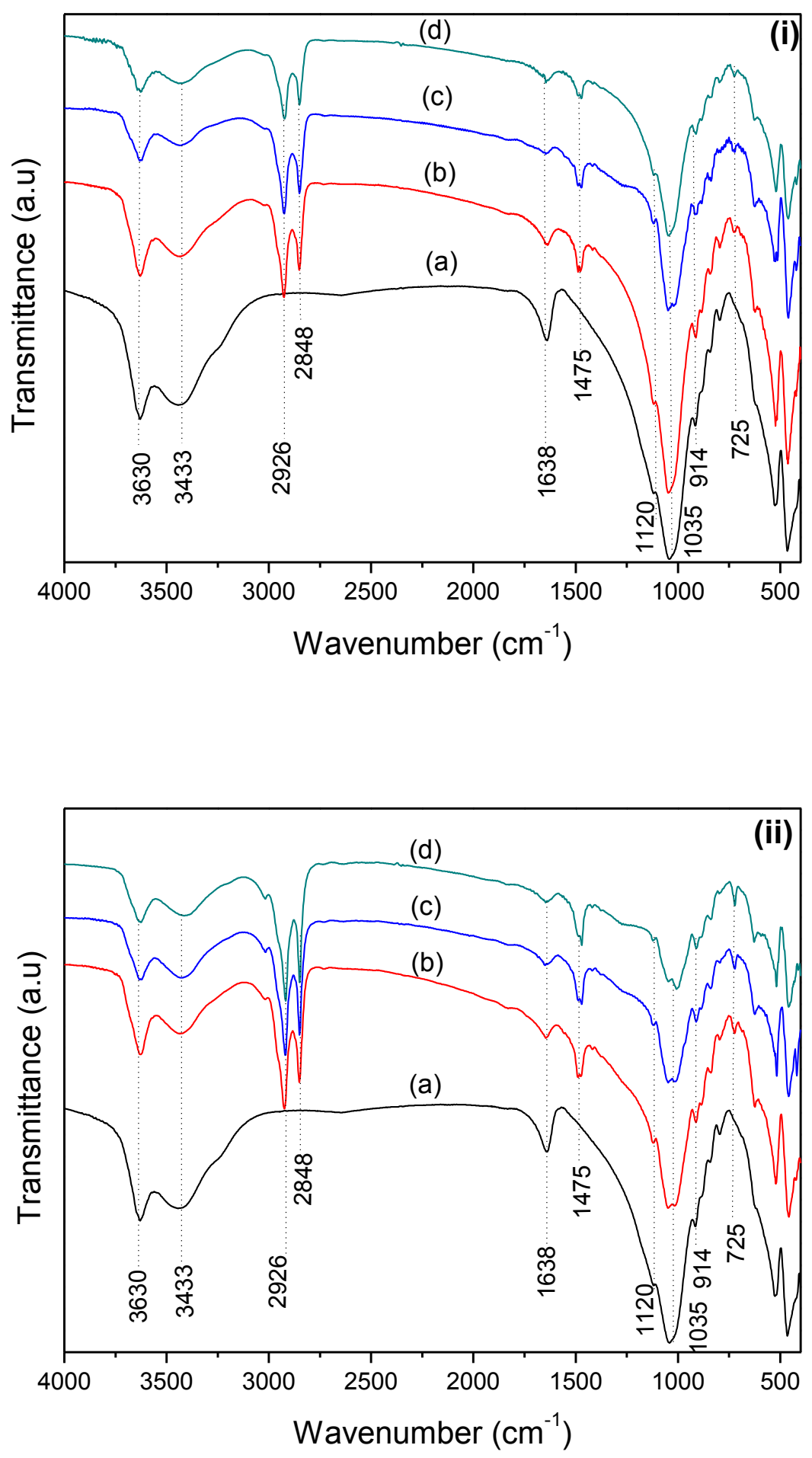

Figure 3. FTIR spectra for (a) pristine and organobentonites obtained with (i) $100 \%$ and (ii) $200 \%$ of CEC using the surfactants (b) C14, (c) C16 and (d) C18. 
For the organobentonites, a displacement in the wavenumbers of the $\mathrm{OH}$ absorptions compared with the spectrum of the pristine solid was not observed. This indicated that interaction is preponderantly in the interlayer region (Xi et al., 2005). New, sharp and strong bands were observed for all hybrids at 2926 and $2848 \mathrm{~cm}^{-1}$ which were assigned to the asymmetric and symmetric $\mathrm{C}-\mathrm{H}$ stretchings of methylene groups (Ouellet-Plamondon et al., 2014; Acisli et al., 2017; Martinez-Costa et al., 2017; Santos et al., 2018) and suggest the presence of the ammonium moieties on the bentonite (Acisli et al., 2017).

For all of the hybrids, both C-H stretching bands were sharp and intense without alterations in the wavenumbers. Other new bands were observed at $1475 \mathrm{~cm}^{-1}$ and 725 $\mathrm{cm}^{-1}$ and were assigned to the scissoring and rocking bending of $\mathrm{CH}_{2}$, respectively (Ouellet-Plamondon et al., 2014; Martinez-Costa et al., 2017; Lazorenko et al., 2018; Santos et al., 2018). The $\mathrm{CH}_{2}$ scissoring band normally overlaps with the $\mathrm{CH}_{3}$ antisymmetrical bending band, which occurs in the same region (Lin-Vien et al. 1995).

\subsection{Thermogravimetry (TG)}

Thermogravimetry analysis was useful to quantify the percentages of organic matter in the solids. The TG results are presented in Figure 4 and Table SM2.

The first mass loss (2.3\%) for pristine bentonite between 298-383 K was attributed to the desorption of external and interlayer water (Park et al., 2011; Ma et al., 2015; Santos et al., 2018) and the second loss of 5\% between $560-1126 \mathrm{~K}$ was associated with the dehydroxylation of bentonite. The percentages of total mass losses between 298-1200 K were higher for organobentonites than pristine bentonite. The first

mass loss associated with the desorption of interlayer water was lower for the 
organobentonites $(<1 \%)$ than the pristine sample, which was attributed to the hydrophilic character of the samples after the organofunctionalization (Moslemizadeh et al., 2016; Santos et al., 2018). The thermal elimination of alkyl surfactants proceeded at temperatures above $473 \mathrm{~K}$. The second, third, fourth and fifth events in the TG curves of the hybrids were attributed to loss of the surfactant moieties and are in agreement with the literature (Park et al., 2011; Zhu et al., 2012; Taleb et al., 2018).

Ma et al (2015) observed a single mass loss with a maximum at $579 \mathrm{~K}$ in the DTG curve and attributed the mass loss to the desorption of the surfactant. In fact, in the present case, an intense loss mass at $579 \mathrm{~K}$ was observed for all hybrids, but multiple mass losses were observed. This fact was associated with the different interactions between the surfactants and bentonite as the concentration of organic moieties increased (Teppen and Aggarwal, 2007; Park et al., 2011; Taleb et al., 2018). The last mass loss for all hybrids $(2.0 \%$, above $799 \mathrm{~K})$ was attributed to the dehydroxylation of the solid (Ma et al., 2015; Santos et al., 2018). 

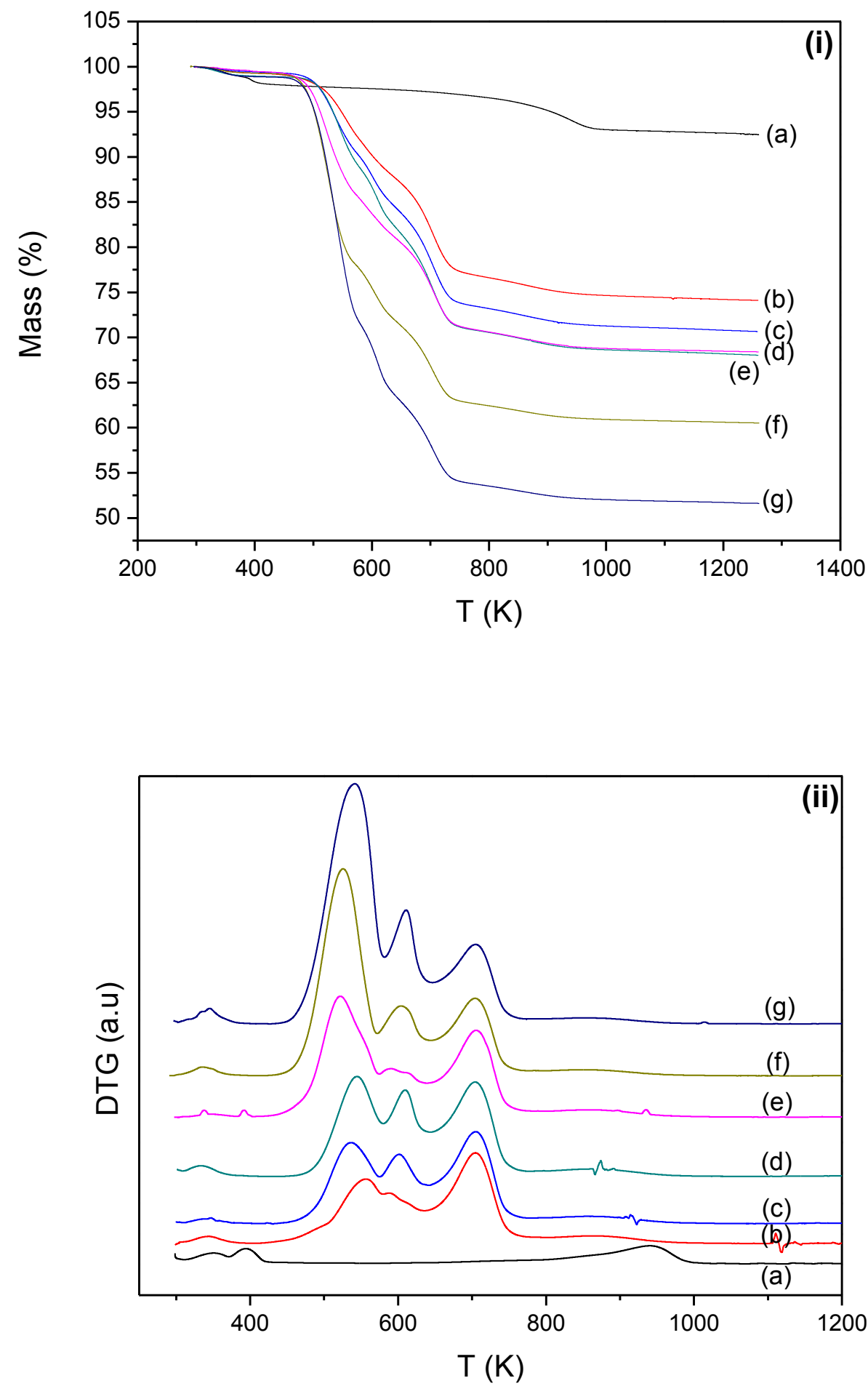

Figure 4. (i) TG and (ii) DTG curves for (a) pristine and organobentonites (b) BentC14-100\%, (c), Bent-C16-100\%, (d) Bent-C18-100\%, (e) Bent-C14-200\%, (f) BentC16-200\% and (g) Bent-C18-200\%. 


\subsection{Zeta potential}

The zeta potential measurement is an important method to define the electrokinetic properties of a surface and determine the point of zero charge $\left(\mathrm{pH}_{\mathrm{PZC}}\right)$ since the anionic dye adsorption is favorable in $\mathrm{pH}$ values lower than the point of zero charge (Yagub et al., 2014). At the point of zero charge, the quantity of positive and negative charges on surface is equal and the net charge is zero (McCafferty, 2010).

Point of zero charge (PZC) is the $\mathrm{pH}$ where the surface charge of a system double-layer reversible is zero, being determined by a particular ion activity, (Parks and Bruyn, 1962). The $\mathrm{pH}_{\mathrm{IEP}}$ (IEP for isoelectric point) and $\mathrm{pH}_{\mathrm{PZC}}$ correspond to the $\mathrm{pH}$ of the aqueous solution, in which amphoteric substances have a neutral charge, however, the $\mathrm{pH}_{\mathrm{IEP}}$ determines the charge of the external surface of the adsorbent particles in solution, and the $\mathrm{pH}_{\mathrm{PZC}}$ results in the total value, that is, the charge of both the internal and external surfaces (Menéndez et al., 1995). The point of zero charge is the $\mathrm{pH}$ value where negative and positive surface concentrations are equal, i.e., surface charge charge is 0 . The surface charge is negative at $\mathrm{pH}>\mathrm{pHpzc}$ and positive at $\mathrm{pH}<\mathrm{pHpzc}$. The isoelectric point is the $\mathrm{pH}$ at which zeta potential of a molecule or surface is equal to zero, $\xi=0$. In order to get a sharp isoelectric point, the surface must be amphoteric, meaning it must have both acidic and basic functional groups. In the simplest case, if the specific sorption of ions and dissociation of counter ions are neglected, then pHpzc coincides with pHiep (Gulicovski et. al., 2008).

Therefore, at $\mathrm{pH}$ values below the point of zero charge $\left(\mathrm{pH}_{\mathrm{PZC}}\right)$, the edges sites of the clay mineral surface are positively charged and the electrostatic interaction is enhanced. At $\mathrm{pH}$ values higher than the PZC, the edges the clay mineral surface was de- 
protonated, the negatively charged dye was barely able to reach the surface adsorption sites.

Bentonite has a net negative charges in aqueous medium independent of the $\mathrm{pH}$ (Swartzen-allen and Matijevic, 1974). The organofunctionalization of the bentonite can modify the surface charge and change it to partially or entirely positive. In this present study, the hybrids prepared with $100 \%$ of the CEC presented $\mathrm{pH}_{\mathrm{PZC}}$ at $4.1 \pm 0.1 ; 10.5$ and $10.5 \pm 0.1$ for Bent-C14-100\%, Bent-C16-100\% and Bent-C18-100\%, respectively. This result indicated that at $\mathrm{pH}$ lower than the point of zero charge, the hybrids are positively charged (Figure 5), favoring in these values the adsorption of the anionic dye. For the hybrids prepared with $200 \%$ of the CEC, a positive surface charge was observed for all $\mathrm{pH}$ values, without a point of zero charge. Therefore, Bent-C14-200\%, Bent$\mathrm{C} 16-200 \%$ and Bent-C18-200\% presented higher dye removal in all $\mathrm{pH}$. The same behavior was observed for other studies in the literature (Ma et al., 2011; Tunç et al., 2012).

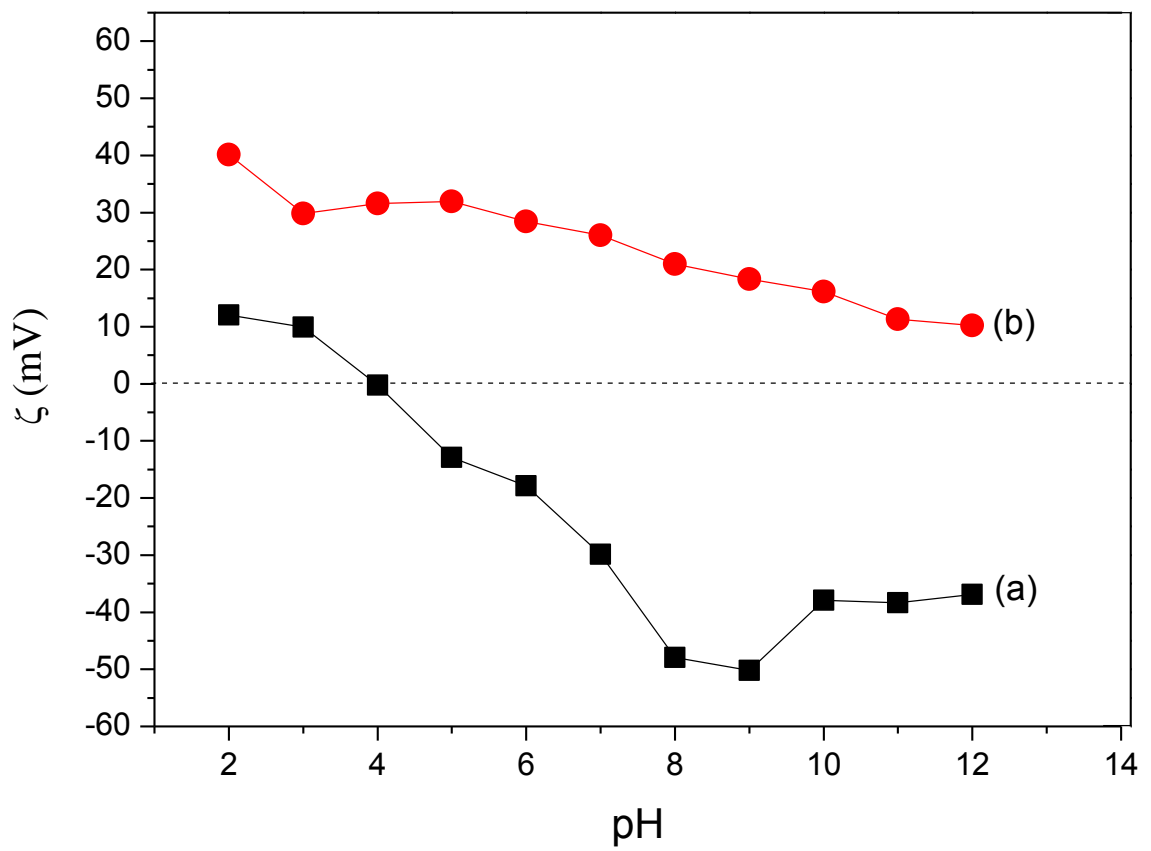




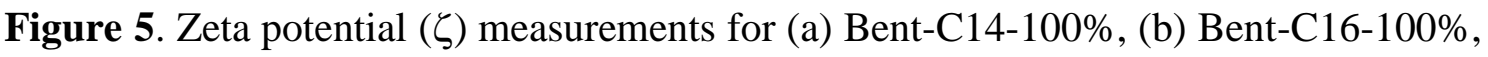

(c) Bent-C18-100\%, (d) Bent-C14-200\%, (e) Bent-C16-200\% and (f) Bent-C18-200\%.

\subsection{Microscopy}

\subsubsection{Scanning electronic microscopy (SEM)}

SEM measurement was used to investigate alterations in the morphology of the solids after reactions with surfactants. SEM images (Figure SM2) showed typical flaky morphology for the pristine bentonite. After organofunctionalization, the solids presented a more irregular surface and dispersed flaky. The same behavior was observed for organobentonites (Santos et al., 2018; Sun et al., 2017).

\subsubsection{Transmission electronic microscopy (TEM)}

TEM micrographs (Figure 6) show that organobentonites maintained the layered structure of the sodium bentonite without the formation of exfoliated phases. The measured interlayer spacings were $1.27,1.82,1.92,2.05,1.82,1.94$ and $2.17 \mathrm{~nm}$ for Bent, Bent-C14-100\%, Bent-C16-100\%, Bent-C18-100\%, Bent-C14-200\%, Bent-C16$200 \%$ and Bent-C18-200\%, respectively and were in concordance with the values of the basal spacing obtained in the XRD analysis. 


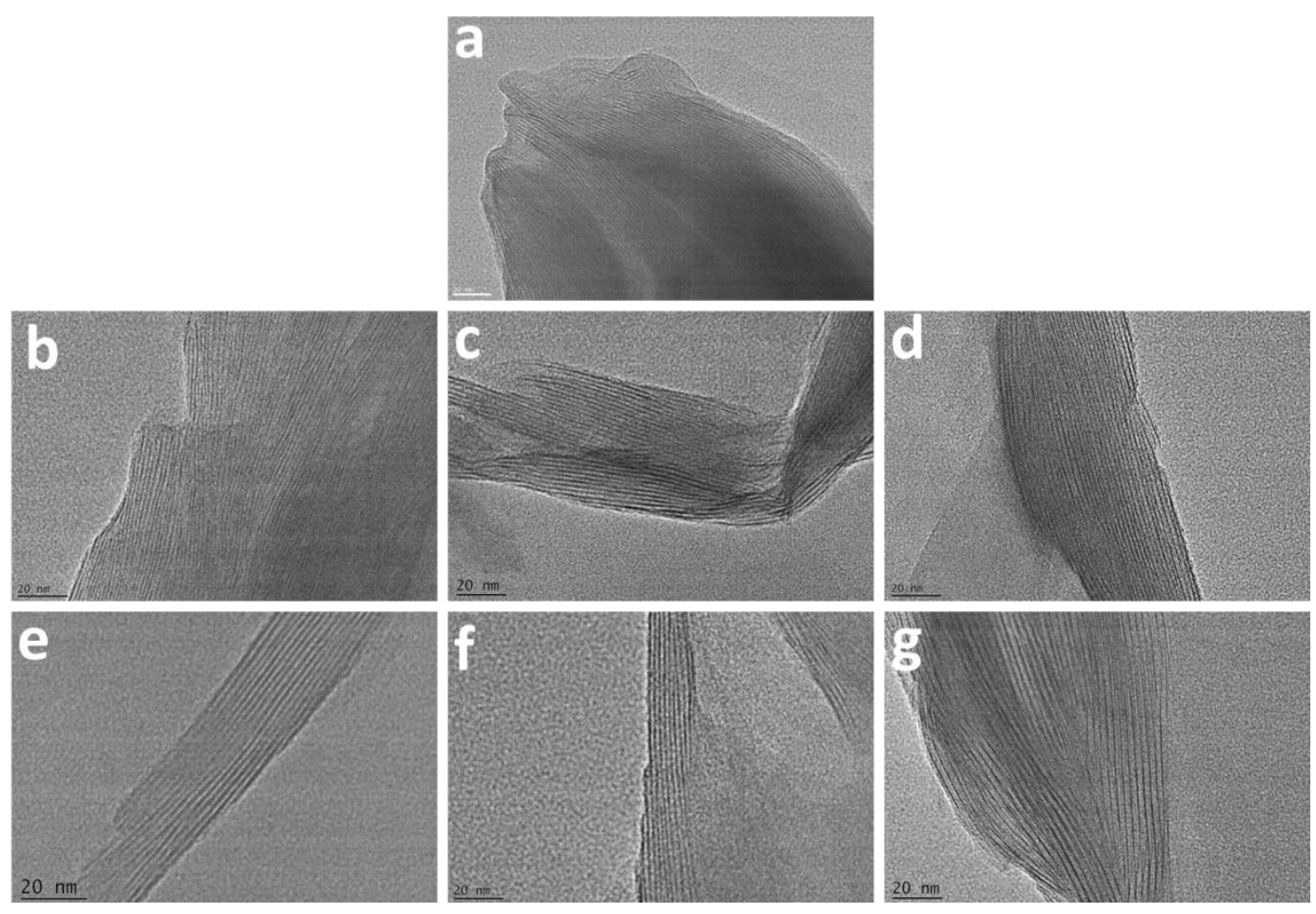

Figure 6. TEM for (a) pristine and organobentonites (b) Bent-C14-100\%, (c), BentC16-100\%, (d) Bent-C18-100\%, (e) Bent-C14-200\%, (f) Bent-C16-200\% and (g) BentC18-200\%.

\subsection{Adsorption}

\subsubsection{Influence of the pH}

The influence of the $\mathrm{pH}$ on adsorption is well-documented due to the charge on the surface and the speciation of the pollutant species in solution (Yagub et al., 2014; Ngulube et al., 2017; Kausar et al., 2018). In acidic conditions, some surfaces are positively charged, and the removal of anionic dye is improved (Ngulube et al., 2017).

The effect of the $\mathrm{pH}$ on $\mathrm{RN}$ blue dye removal is shown in Figure 7 for the test at $303 \mathrm{~K}$ with $50 \mathrm{mg}$ and a $500 \mathrm{mg} \cdot \mathrm{L}^{-1}$ dye concentration. 
The dye removal by the three hybrids obtained with $100 \%$ of the CEC was pH dependent, and the highest value of retained dye was at a $\mathrm{pH}$ of 2.0. This behavior agrees with the positive charge $(20-36 \mathrm{mV})(\mathrm{pH}<4.1)$ based on zeta potential measurements. The Bent-C14-100\% sample showed a dye removal of $160 \mathrm{mg} \mathrm{g}^{-1}$ at a $\mathrm{pH}$ of 2.0 , while the value was $173 \mathrm{mg} \cdot \mathrm{g}^{-1}$ for both Bent-C16-100\% and Bent-C18$100 \%$ under the same conditions. Early studies reported that lower $\mathrm{pH}$ values contribute to higher adsorption (Ozcan et al., 2007; Ma et al., 2011).

For the hybrids obtained using $200 \%$ of the CEC (Figura 7ii), the behavior was different. Indeed, the performances of the solids were very close, and these results are in opposition to the zeta potential measurements since the hybrids synthesized with $200 \%$ of the CEC showed a positive surface throughout the entire $\mathrm{pH}$ range. A similar result was observed by Yan et al., (2015). It is possible that the electrostatic force is the principal factor in relation to the affinity between the dye and the hybrids, but the amount of the organocations in the hybrid influenced the adsorption (Zhang et al., 2016). Therefore, the maximum removal was close to $206 \mathrm{mg} \cdot \mathrm{g}^{-1}$ for Bent-C14-200\% at $\mathrm{pH}$ values in the range of 3.0 to 7.0 , and the minimum value was $188.3 \mathrm{mg} \cdot \mathrm{g}^{-1}$ at a $\mathrm{pH}$ of 2.0. The Bent-C16-200\% and Bent-C18-200\% hybrids presented almost the same behavior and maximum adsorption values of $169 \mathrm{mg} \cdot \mathrm{g}^{-1}$. For Bent-C14-200\%, the maximum adsorption was higher than $99 \%$ at all $\mathrm{pH}$ values, while the maximum values were $82 \%$ and minimum $62 \%$ for Bent-C16-200\% and maximum $78 \%$ and minimum $66 \%$ for Bent-C18-200\%.

Considering that many residual waters have $\mathrm{pH}$ values in the range of 6.0 to 9.0 (Yan et al., 2015), the hybrids prepared with $200 \%$ of the CEC have the advantage with regards to practical applications because $\mathrm{pH}$ adjustment of the solution is not necessary. 

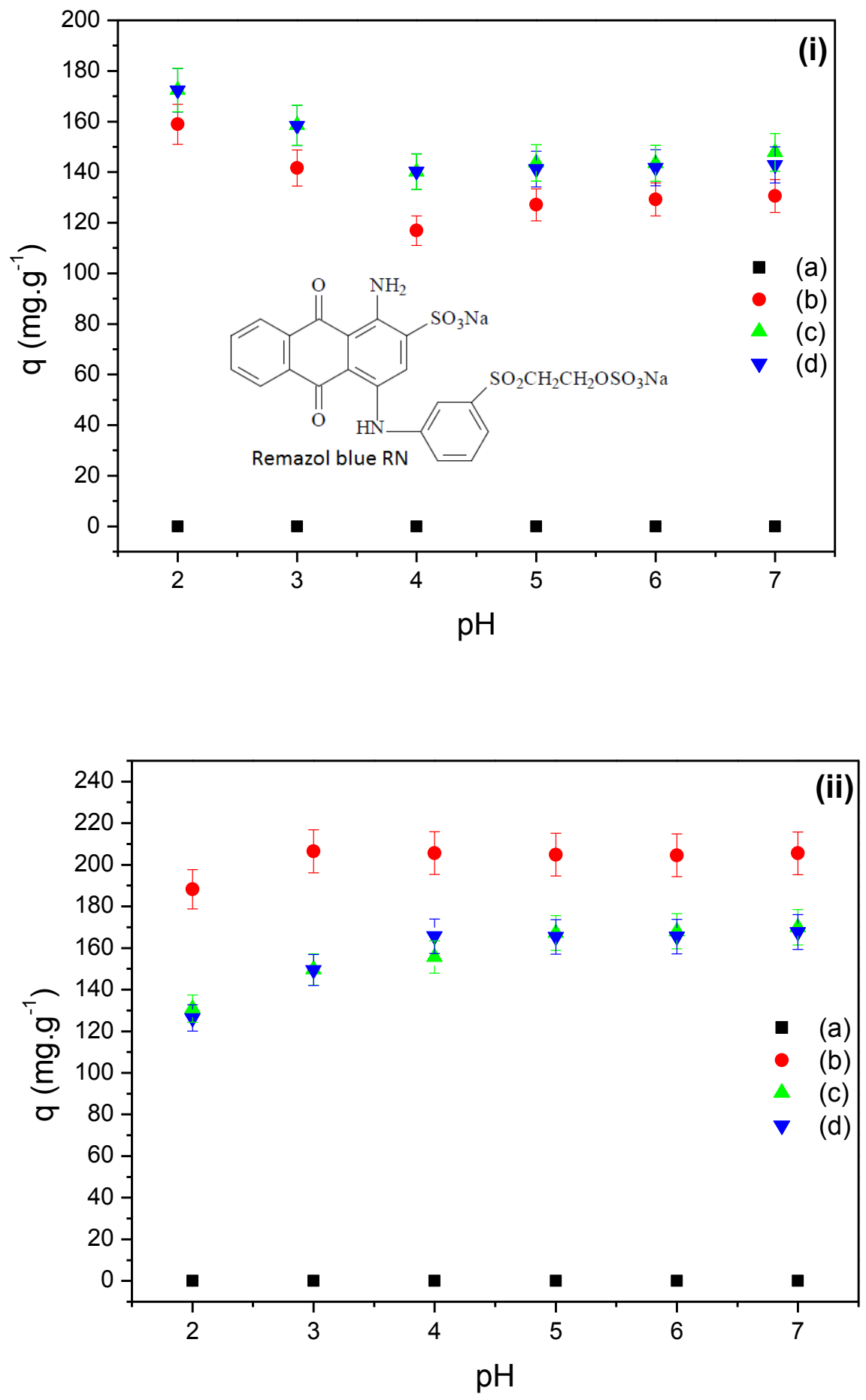

Figure 7. Effect of the $\mathrm{pH}$ on adsorption of remazol blue $\mathrm{RN}$ (inserted figure) by (a) pristine and organobentonites obtained with (i) $100 \%$ and (ii) $200 \%$ of CEC using the 
surfactants (b) C14, (c) C16 and (d) C18 at $303 \mathrm{~K}$. Conditions: $50 \mathrm{mg}$ of solid, $20 \mathrm{~mL}$ of the $500 \mathrm{mg} \mathrm{L}^{-1}$ dye solution, contact time of $24 \mathrm{~h}, \mathrm{pH} 2.0$ to 7.0 at $303 \mathrm{~K}$.

\subsubsection{Dosage of the adsorbent}

The influence of the adsorbent dosage (Figure SM3) was monitored by contacting different amounts of the solid $(25-100 \mathrm{mg})$ with $20 \mathrm{~mL}$ of a $500 \mathrm{mg} \cdot \mathrm{L}^{-1}$ dye concentration at $303 \mathrm{~K}$ and a pH 2.0 for the maximum removal for $24 \mathrm{~h}$.

The adsorption efficiency of solids initially increases with the adsorbent dosage, and it finally reaches a plateau. The optimum dosage for dye removal was found to be $75 \mathrm{mg}$ of solid for all hybrids synthesized by using $100 \%$ and $200 \%$ of the CEC, except for Bent-C16-200\%, for which the better dosage was $100 \mathrm{mg}$. Generally, the increase in adsorption efficiency with increasing the amount of the adsorbent in the system is associated with the availability of more adsorption sites resulting from the increase in adsorbent particles (Ngulube et al., 2017). The optimum adsorbent dose is mainly related to availability of active site but also is directly linked with the concentration of the adsorbate (Iftekhar et al., 2018). The effect of the adsorbent dosage gives an idea of the capacity of an adsorbent in the adsorption of a determined dye, so as to use the

smaller amount of adsorbent needed for determined experimental condition and concentration of adsorbate used (Yagub et al., 2014). By the other hand, at lower adsorbent dosage, the adsorption rate is quick because of the readily available active sites and when the adsorbent dosage is high, the dye ions cannot readily access the adsorption sites easily until the attainment of equilibrium (Sarma et al., 2016). 


\subsubsection{Effect of time on the adsorption}

The adsorption kinetics were evaluated by contacting 75 or $100 \mathrm{mg}$ of the solid with $20 \mathrm{~mL}$ of the $500 \mathrm{mg} \cdot \mathrm{L}^{-1}$ dye solutions at the optimum $\mathrm{pH}$ (Figure 8). Corroborating with the literature, the adsorption was fast during the first few minutes of the interaction, and after $20 \mathrm{~min}$, all of the solids obtained with $100 \%$ of the CEC adsorbed $100 \mathrm{mg} \cdot \mathrm{g}^{-1}$, reaching a dye removal higher than $>95 \%$. The behavior was similar and the equilibrium was reached after 60 min with an adsorption capacity of close to $125 \mathrm{mg} \cdot \mathrm{g}^{-1}$ for all hybrids.

For the hybrids obtained with $200 \%$ of the CEC, the equilibrium time was achieved after $60 \mathrm{~min}$ with maximum removals close $140 \mathrm{mg} \cdot \mathrm{g}^{-1}$, except for Bent-C16$200 \%$, for which the equilibrium time was $240 \mathrm{~min}$.

In order to interpret the adsorption kinetics, the pseudo-first-order, pseudosecond-order and Elovich models were applied (Figure SM4). The kinetic parameters of the fittings for the cited models are presented in Table 2. The higher $\mathrm{R}^{2}$ regression and lower difference between the $\mathrm{q}_{\mathrm{e}, \mathrm{exp}}$ and $\mathrm{q}_{\mathrm{e} \text {,theor }}$ show that the experimental data were well-fitted to the pseudo-second-order model. The fit of this model indicates that adsorption rate is controlled by chemisorption process, which involves valence forces from the sharing of electrons between dye molecules and material surface (Foo et al., 2012; Silva 2016). Other studies related to adsorption of the same dye on different adsorbents demonstrated the same behavior (Pereira et al., 2017; Silva et al., 2012; Malakootian et al., 2015). 

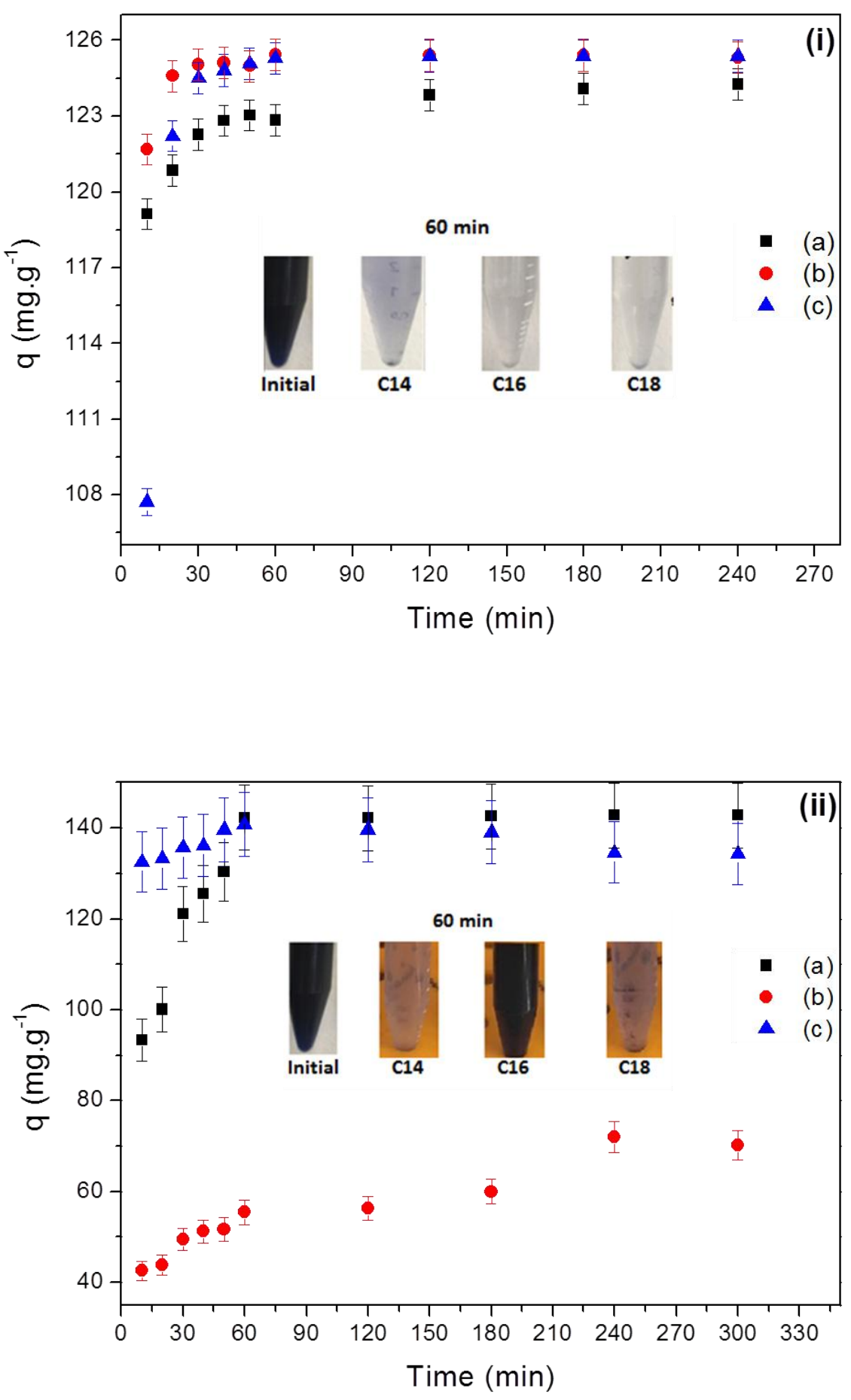

Figure 8. Time isotherms for the adsorption of remazol blue RN by (a) pristine and organobentonites obtained with (i) $100 \%$ and (ii) $200 \%$ of the CEC using the surfactants (b) C14, (c) C16 and (d) C18. Conditions: 75 or $100 \mathrm{mg}$ of solid, $20 \mathrm{~mL}$ of the $500 \mathrm{mg}$ $\mathrm{L}^{-1}$ dye solution, contact times of $60-240 \mathrm{~min}, \mathrm{pH} 2.0$ or 6.5 at $303 \mathrm{~K}$. 
Table 2. Kinetic parameters obtained by fitting the adsorption data of Remazol blue RN on organobentonites to pseudo-first order, pseudo-second order and Elovich models. 


\begin{tabular}{|c|c|c|c|c|}
\hline Hybrid & $\begin{array}{c}\mathrm{q}_{\mathrm{e}, \exp } \\
\left(\mathrm{mg} \mathrm{g}^{-1}\right)\end{array}$ & $\begin{array}{l}\mathrm{q}_{\mathrm{e}}, \text { theor } \\
\left(\mathrm{mg} \mathrm{g}^{-1}\right)\end{array}$ & $\begin{array}{c}\mathrm{k}_{1} \\
10^{-2}\left(\mathrm{~min}^{-1}\right)\end{array}$ & $\mathrm{R}^{2}$ \\
\hline Bent-C14-100\% & 123.0 & 12.6 & 9.82 & 0.9619 \\
\hline Bent-C16-100\% & 125.4 & 3.3 & 5.22 & 0.5684 \\
\hline Bent-C18-100\% & 125.4 & 28.2 & 9.69 & 0.9461 \\
\hline Bent-C14-200\% & 142.8 & 49.9 & 3.00 & 0.7148 \\
\hline Bent-C16-200\% & 75.1 & 29.2 & 0.20 & 0.3908 \\
\hline Bent-C18-200\% & 140.7 & 16.6 & 4.40 & 0.7092 \\
\hline \multicolumn{5}{|c|}{ Pseudo-second order } \\
\hline Hybrid & $\begin{array}{c}\mathrm{q}_{\mathrm{e}, \exp } \\
\left(\mathrm{mg} \mathrm{g}^{-1}\right)\end{array}$ & $\begin{array}{l}\mathrm{q}_{\mathrm{e}, \text { theor }} \\
\left(\mathrm{mg} \mathrm{g}^{-1}\right)\end{array}$ & $\begin{array}{c}\mathrm{k}_{2} \\
10^{-2}\left(\mathrm{~g} \mathrm{mg}^{-1} \min ^{-1}\right)\end{array}$ & $\mathrm{R}^{2}$ \\
\hline Bent-C14-100\% & 123.0 & 124.2 & 1.68 & 0.9999 \\
\hline Bent-C16-100\% & 125.4 & 125.9 & 2.87 & 0.9999 \\
\hline Bent-C18-100\% & 125.4 & 126.8 & 0.91 & 0.9998 \\
\hline Bent-C14-200\% & 142.8 & 166.7 & 0.07 & 0.9998 \\
\hline Bent-C16-200\% & 75.1 & 71.4 & 0.07 & 0.9345 \\
\hline Bent-C18-200\% & 140.7 & 142.8 & 0.54 & 0.9992 \\
\hline \multicolumn{5}{|c|}{ Elovich } \\
\hline Hybrid & $\begin{array}{c}\mathrm{q}_{\mathrm{e}, \exp } \\
\left(\mathrm{mg} \mathrm{g}^{-1}\right)\end{array}$ & $\begin{array}{c}\alpha \\
\left(\mathrm{mg} \mathrm{g}^{-1}\right. \\
\left.\min ^{-1}\right)\end{array}$ & $\begin{array}{c}\beta \\
\left(\mathrm{g} \mathrm{mg}^{-1}\right)\end{array}$ & $\mathrm{R}^{2}$ \\
\hline Bent-C14-100\% & 123.0 & $4.7610^{19}$ & 0.3917 & 0.9785 \\
\hline Bent-C16-100\% & 125.4 & $4.1110^{27}$ & 0.5331 & 0.7447 \\
\hline Bent-C18-100\% & 125.4 & $3.1110^{7}$ & 0.1555 & 0.5649 \\
\hline Bent-C14-200\% & 142.8 & 532.03 & 0.0594 & 0.8248 \\
\hline Bent-C16-200\% & 75.1 & 146.46 & 0.1331 & 0.5999 \\
\hline Bent-C18-200\% & 140.7 & $1.3110^{12}$ & 0.2184 & 0.8129 \\
\hline
\end{tabular}

\subsubsection{Effect of the initial dye concentration}


Equilibrium isotherms for the adsorption of Remazol Blue RN on organobentonites are shown in Figure 8. Studies reported that dye removal increased with the increase of the initial dye concentration until saturation is reached (Makhoukhi et al., 2015; Ngulube et al., 2017).

The initial dye concentration of Remazol blue RN modified the quantity of adsorbed dye on the different solids until equilibrium (Figure 9), where saturation occurred at the initial concentration of $1000 \mathrm{mg} \mathrm{L}^{-1}$ for solids obtained with $100 \%$ of the CEC and $1200 \mathrm{mg} \mathrm{L}^{-1}$ for those prepared with $200 \%$ of the CEC. The maximum retentions were 195, 199 and $209 \mathrm{mg} \mathrm{g}^{-1}$ for Bent-C14-100\%, Bent-C16-100\% and Bent-C18-100\% as well as 211, 163 and $287 \mathrm{mg} \mathrm{g}^{-1}$ for Bent-C14-200\%, Bent-C16$200 \%$ and Bent-C18-200\%, respectively.

The equilibrium data were adjusted to Langmuir, Freundlich and Temkin models (Figure SM5), and the resulting parameters are summarized in Table 3.

Taking into account the coefficients of correlation $\left(\mathrm{R}^{2}\right)$, the better adjustments were observed for the Langmuir model for all of the investigated systems, indicating that chemisorption can be the preponderant mechanism involved in the Remazol blue $\mathrm{RN}$ dye removal. 

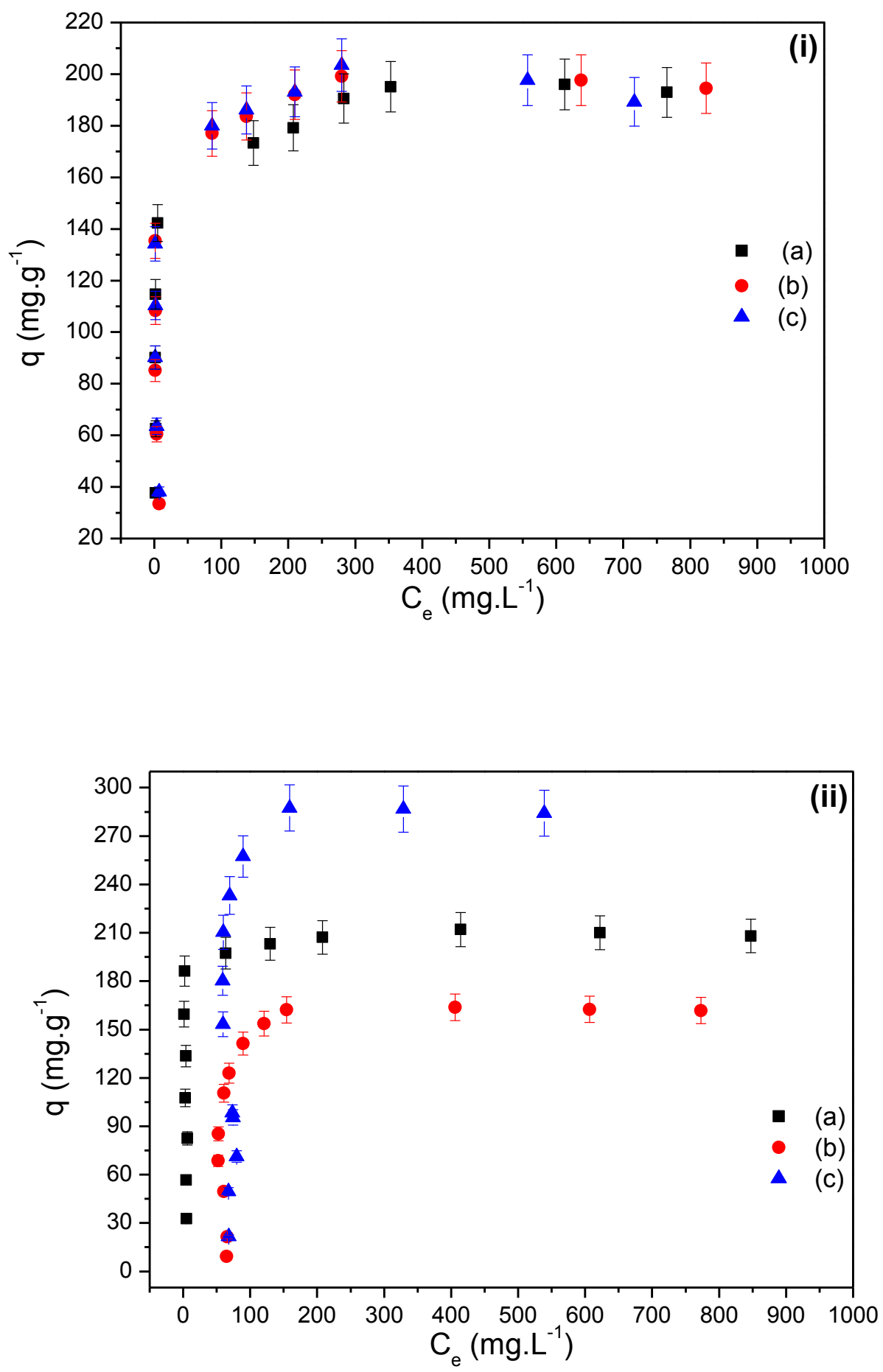

Figure 9. Equilibrium isotherms for the adsorption of remazol blue RN by (a) pristine and organobentonites obtained with (i) $100 \%$ and (ii) $200 \%$ of the CEC using the surfactants (b) C14, (c) C16 and (d) C18. Conditions: 75 or $100 \mathrm{mg}$ of solid, $20 \mathrm{~mL}$ of the $100-1400 \mathrm{mg} \mathrm{L}^{-1}$ dye solution, 60 or $240 \mathrm{~min}$, $\mathrm{pH} 2.0$ or 6.5 at $303 \mathrm{~K}$. 
Table 3. Parameters obtained by fitting the adsorption data of Remazol blue RN on organobentonites to Langmuir, Freundlich and Temkin models.

\begin{tabular}{|c|c|c|c|}
\hline \multicolumn{4}{|c|}{ Langmuir } \\
\hline Hybrid & $\begin{array}{c}\mathrm{q}_{\exp } \\
\left(\mathrm{mg} \mathrm{g}^{-1}\right)\end{array}$ & $\begin{array}{c}\mathrm{q}_{\mathrm{e}, \text { theor }} \\
\left(\mathrm{mg} \mathrm{g}^{-1}\right)\end{array}$ & $\mathrm{R}^{2}$ \\
\hline Bent-C14-100\% & 192.9 & 200.0 & 0.9992 \\
\hline Bent-C16-100\% & 194.5 & 200.0 & 0.9984 \\
\hline Bent-C18-100\% & 205.4 & 250.0 & 0.9996 \\
\hline Bent-C14-200\% & 211.9 & 250.0 & 0.9961 \\
\hline Bent-C16-200\% & 163.7 & 169.4 & 0.9985 \\
\hline Bent-C18-200\% & 287.4 & 361.1 & 0.9933 \\
\hline \multicolumn{4}{|c|}{ Freundlich } \\
\hline \multicolumn{4}{|c|}{$\left(\mathrm{mg} \mathrm{g}^{-1}\right)\left(\mathrm{mg} \mathrm{L}^{-1}\right)^{-1 / n}$} \\
\hline Bent-C14-100\% & 5.9524 & 70.74 & 0.6445 \\
\hline Bent-C16-100\% & 6.3694 & 72.82 & 0.4085 \\
\hline Bent-C18-100\% & 6.2112 & 82.35 & 0.5763 \\
\hline Bent-C14-200\% & 6.6445 & 84.02 & 0.1652 \\
\hline Bent-C16-200\% & 1.3928 & 3.06 & 0.1420 \\
\hline Bent-C18-200\% & 1.1429 & 2.73 & -0.0060 \\
\hline \multicolumn{4}{|c|}{ Temkin } \\
\hline Hybrid & $\mathrm{b}_{\mathrm{T}}$ & $\mathrm{A}_{\mathrm{T}}$ & $\mathrm{R}^{2}$ \\
\hline Bent-C14-100\% & 126.00 & 43.07 & 0.8182 \\
\hline Bent-C16-100\% & 127.64 & 48.77 & 0.6310 \\
\hline Bent-C18-100\% & 123.24 & 82.99 & 0.7474 \\
\hline Bent-C14-200\% & 126.26 & 107.89 & 0.3130 \\
\hline Bent-C16-200\% & 40.38 & 0.05 & 0.3974 \\
\hline Bent-C18-200\% & 17.13 & 0.03 & 0.1165 \\
\hline
\end{tabular}


The same behavior was observed in other studies for bentonites modified by surfactants applied in dye adsorption, which were adjusted to the pseudo second order model kinetic (Anirudhan et al., 2015; Yan et al., 2015; Sahnoun et al., 2018) and to the Langmuir model equilibrium (Ren et al., 2018; Sahnoun et al., 2018; ).

Table SM3 shows the adsorption capacity for remazol blue RN dye by different adsorbents including alginate gel beads (Ergene et al., 2009), modified montmorillonites (Silva et al., 2012; Pereira et al., 2017), activated carbon (Isah et al., 2015; Silva et al. 2016); alumina-coated multi-walled carbon nanotubes (Malakootian et al., 2015) and porous nano-crystalline $\mathrm{CoFe}_{2} \mathrm{O}_{4}$ composite (Khan et al., 2015).

The XRD patterns and infrared spectra of the hybrids after the adsorption process of the Remazol blue $\mathrm{RN}$ did not have significant variations attributed to the overlapping of the absorptions since the bands of the dye occur in the same region of the organobentonite. Solid state UV-VIS spectra showed a new band at approximately $592 \mathrm{~nm}$ attributed to Remazol blue RN dye (Figure SM6).

Based on zeta potential measurements and the $\mathrm{pH}$ isotherms and kinetic and equilibrium models, the preponderant mechanism of adsorption could be electrostatic interaction between the anionic dye and the alkyl ammonium moieties disposed in the interlayer spacing and external surface of the montmorillonite and also the chemisorption process (Figure SM7) (Zhang et al., 2016). However, the present set of techniques are not conclusive about the chemical forces between the dye and the surface. Another possible mechanism is by anion exchange between the bromides intercalated as counter ions in the ionic pair with the cations. Some works have proposed the interaction by anion exchange involving the dye and $\mathrm{Br}^{-}$previously 
intercalated as the counter ion of the ammonium salt (Ma et al., 2011; Sun et al., 2017; Sahnoun et al., 2018).

In order to check this hypothesis, qualitative tests were carried out with silver nitrate solution in the supernatant obtained after the adsorption process. The formation of a white precipitate was associated with the presence of bromide ions in the supernatant, indicating that anion exchange between the $\mathrm{Br}^{-}$in the montmorillonite and the anionic dye in solution contributed to the removal. As a control, the procedure was repeated by suspending the organobentonites in distilled water, and no precipitate was formed, indicating the absence of bromides on the solid due insufficient washing. Therefore, the presence of bromide ions in the supernatant after dye adsorption was associated with the anion exchange mechanism.

\subsubsection{Desorption test}

This study was performed to evaluate the regeneration capacity of the adsorbent for reuse. The desorption test defines whether the potential of the solid for reuse or stability of the dye/solid complex for other purposes, such as pigment. The reusability is one of the important characteristics of any kind of adsorbents and is a critical point on the economy of the process (Salehi et al., 2016). However, in recent years great importance was given to the preparation of new stable pigments based on clay minerals (Fournier et al., 2016; Zhang et al., 2017; Guillermin et al., 2018; Trigueiro et al., 2018). The study of new materials includes the search for new pigments by immobilization of the dyes in resistant substrates such clays minerals to get new color fonts and materials with high stability (Fournier et al., 2016; Trigueiro et al., 2018). 
Some studies show that acid and basic solutions are favorable to desorption (Sathishkumar et al., 2012; Anirudhan et al., 2015; Salehi et al., 2016). In the present work, the dye/bentonite hybrid presented high stability and did not show any desorption in any of the acid and basic solutions.

\subsection{Adsorption with simulated dye effluent}

UV-VIS spectra (Figure SM8) of the synthetic effluent before and after adsorption were recorded in the range of $190-900 \mathrm{~nm}$. The tests were conducted at natural $\mathrm{pH}$ of the dye solution 6.4 , and a controlled $\mathrm{pH}$ of 2.0 for $3 \mathrm{~h}$ at room temperature. The absorbance of the mixture was monitored and used to calculate the dye concentration in solutions before and after the interaction with the organobentonites.

For all of the hybrids, the absorbance in the monitored wavenumbers $\left(\lambda_{\max }=412\right.$ $\mathrm{nm}$, Remazol yellow GR dye; $\lambda_{\max }=540 \mathrm{~nm}$, Remazol red RB dye; and $\lambda_{\max }=609 \mathrm{~nm}$, Remazol blue RN dye) decreased significantly after adsorption (Figure 10 and Figure SM9). For Bent-C14-100\% and Bent-C14-200\%, the dye removals were very close to $100 \%$ at $\mathrm{pH}$ 6.4. The Bent-C16-100\% and Bent-C18-100\% showed higher decay in the absorptions than Bent-C16-200\% and Bent-C18-200\%. Therefore, for the dye mixtures, the high amounts of the organic moieties were not a preponderant factor due the competition between the anionic dyes and the higher packing density of the solids with long organic moieties. 


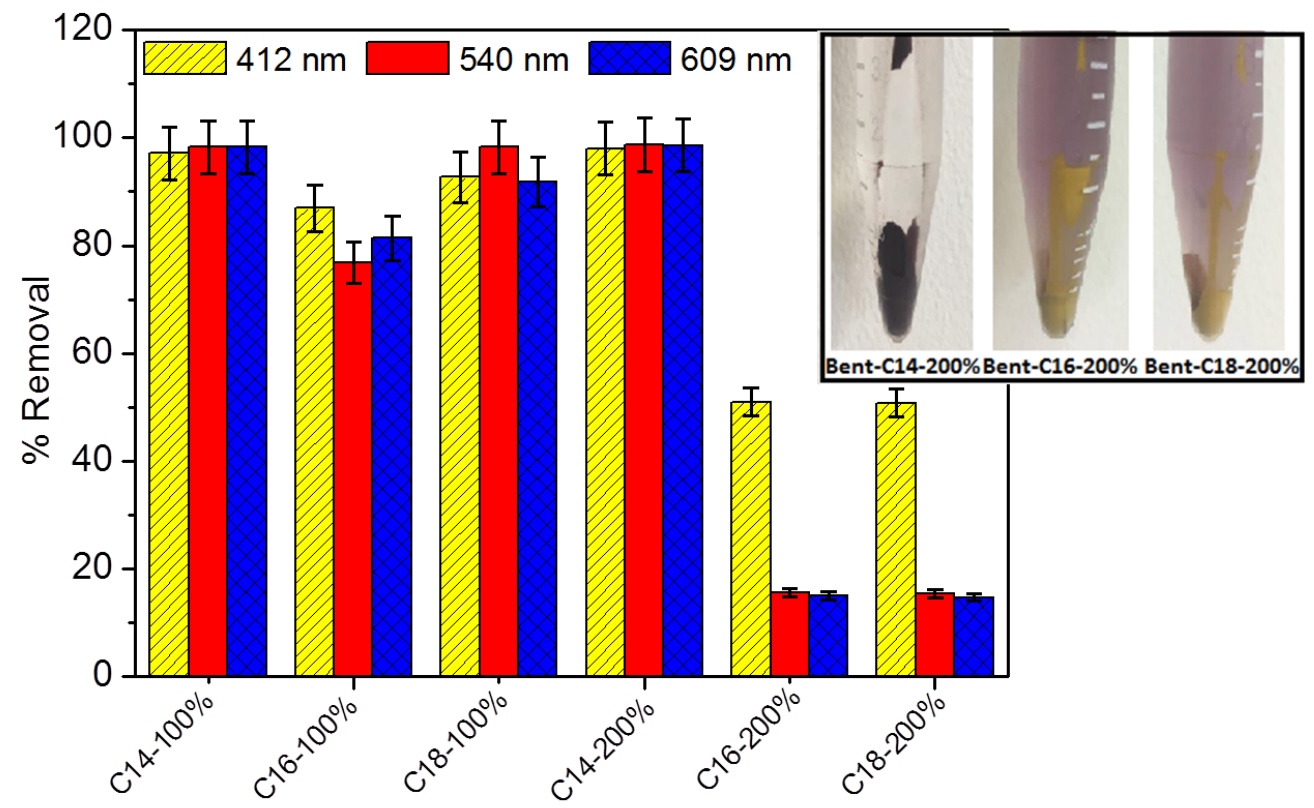

Figure 10. Results for the removal of the dyes at $\mathrm{pH}$ value of 6.4 in a synthetic effluent. The macroscopic picture is the solution after centrifugation using Bent-C14-200\%, Bent-C16-200\%, Bent-C18-200\%.

The best results were for Bent-C14-100\% and Bent-C14-200\%, with removals close $98 \%$ and 99\%, respectively. Bent-C16-200\% and Bent-C18-200\% hybrids presented less efficiency to remove all of the dye in the mixture; however both hybrids were selective for Remazol yellow GR, which has a maximum absorbance at $412 \mathrm{~nm}$. The insert image in Figure 9 shows the macroscopic picture of the systems with the synthetic effluent, and while the solution is clear after removal using Bent-C14-200\%, there is color in the suspension after the interaction with Bent-C16-200\% and BentC18-200\%. However, both solids were yellow after adsorption in the synthetic effluent. 
It was observed that Bent-C14 showed the best performance for Remazol blue $\mathrm{RN}$ and for the dyes in the synthetic effluent. The behavior of Bent-C14 was associated with the lower density packing of the organic moieties compared with Bent-C18, as suggested in the literature (Heinz, 2011).

\section{CONCLUSIONS}

The use of microwave heating for the preparation of organobentonites at $323 \mathrm{~K}$ is a rapid and efficient methodology $(5 \mathrm{~min})$. The prepared solids showed the intercalation of surfactant molecules into the interlayer spacing with basal spacings varying in the range of 1.83 to $2.00 \mathrm{~nm}$.

The organosolids have good performance for dye removal from aqueous solution, although increasing the amount and the length of organic alkyl chain for hybrids prepared with $100 \%$ and $200 \%$ of the CEC did not result in a higher efficiency of the solids. The change in the surface charge of organobentonites contributed to high Remazol blue RN removal as well as good removal of the dyes in the synthetic effluent. The best performance in both tests was for Bent-C14-100\% and Bent-C14-200\%. Furthermore, the Bent-C14-200\% was efficient in acidic conditions and at the $\mathrm{pH}$ of the dye solution. The Bent-C16-200\% and Bent-C18-200\% hybrids were selective for Remazol yellow GR.

\section{Acknowledgements}

$\mathrm{CNPq}$ is acknowledged for providing research fellowships to MG Fonseca and EC Silva Filho and CAPES/COFECUB (835/15) for financial support. 


\section{REFERENCES}

Açişli, Ö., Karaca, S., Gürses, A., 2017. Investigation of the alkyl chain lengths of surfactants on their adsorption by montmorillonite (Mt) from aqueous solutions. Appl. Clay Sci. 142, 90-99.

Aksu, Z., Dönmez, G., (2003). A comparative study on the biosorption characteristics of some yeasts for Remazol Blue reactive dye. Chemosphere, 50(8), 1075-1083.

Alves, J.L., Rosa, P.T.V., Moralesa, A.R., 2017. Evaluation of organic modification of montmorillonite with ionic and nonionic surfactants. Appl. Clay Sci. 150, 23-33.

Anirudhan, T.S., Ramachandran, M., 2015. Adsorptive removal of basic dyes from aqueous solutions by surfactant modified bentonite clay (organoclay): kinetic and competitive adsorption isotherm. Process Saf. Environ. Prot. 95, 215-225.

Bedin, K.C., Azevedo, S.P., Leandro, P.K.T., André L. Cazetta, A.L., Almeida, V.C., 2017. Bone char prepared by CO2 atmosphere: Preparation optimization and adsorption studies of Remazol Brilliant Blue R. J. Clean. Prod. 161, 288-298.

Bergaya, F., Jaber, M., Lambert, J.F., 2011. Clay Clay Miner. In: Rubber-clay nanocomposites: science, Technology and Applications. 1. ed. Roboken: Editora John Wiley e Sons.

Brigatti, M.F., Galán, E.,. Theng, B.K.G., 2013. Structure and mineralogy of clay minerals. In Clay Science, Handbook of Clay Science and mineralogy of clay minerals. 5, 21-81.

Chiu, C. W., Huang, T. K., Wang, Y. C., Alamani, B. G., Lin, J. J., 2014. Intercalation strategies in clay/polymer hybrids. Prog. Polym. Sci. 39, 443-485. 
Daoudi, E., Boughaleb, Y., El Gaini, L., Meghea, I., Bakasse, M., 2013. Modeling of alkyl quaternary ammonium cations intercalated into montmorillonite lattice. Mater. Res. Bull. 48, 1824-1829.

Dohrmann, R., 2006. Cation exchange capacity methodology I: An efficient model for the detection of incorrect cation exchange capacity and exchangeable cation results. Appl. Clay Sci. 34, 31-37.

Duane, M.M., Robert, C.R., 1997. X-Ray Diffraction and the identification and analysis of clay minerals. Oxford University Press, Oxford, New York, pp. 227-259.

Elfadl, A.M.; Zeid, I.F.; Yehia, F.Z.; Abouelela, M.M.; Rabie, A.M., 2017. Production of aromatic hydrocarbons from catalytic pyrolysis of lignin over acid-activated bentonite clay. Fuel Process. Technol. 163, 1-7.

Elovich, S.Y., Larinov, O.G., 1962. Theory of adsorption from solutions of non electrolytes on solid (I) equation adsorption from solutions and the analysis of its simplest form, (ii) verification of the equation of adsorption isotherm from solutions. Izv Sib Otd An Khim 2, 209-216.

Ergene, A., Ada, K., Tan, S., Katırcıoğlu, H., 2009. Removal of Remazol Brilliant Blue $\mathrm{R}$ dye from aqueous solutions by adsorption onto immobilized Scenedesmus quadricauda: Equilibrium and kinetic modeling studies. Desalination, 249, 13081314.

Fabryanty, R.; Valencia, C.; Soetaredjo, F. E.; Putro, J. N.; Santoso, S. P.; Kurniawan, A.; Ju, Y.; Ismadji, S., 2017. Removal of Crystal Violet Dye by Adsorption Using Bentonite - Alginate Composite. J. Environ. Chem. Eng. 5, 5677-5687.

Fan, H., Zhou, L., Jiang, X., Huang, Q., Lang, W., 2014. Adsorption of $\mathrm{Cu}^{2+}$ and methylene blue on dodecyl sulfobetaine surfactant-modified montmorillonite. Appl. Clay Sci. 95, 150-158. 
Farias, A. F. F.; Moura, K. F.; Souza, J. K. D.; Lima, R. O.; Nascimento, J. D. S. S.; Cutrim, A. A.; Longo, E.; Araújo, A. S.; Carvalho-Filho, J. R.; Souza, A. G.; Santos, I. M. G., 2015. Biodiesel obtained by ethylic transesterification using $\mathrm{CuO}, \mathrm{ZnO}$ and $\mathrm{CeO}_{2}$ supported on bentonite. Fuel. 160, 357-365.

Fatimah, I.; Wang, D.; Wulandar, I., 2011. ZnO/montmorillonite for photocatalytic and photochemical degradation of methylene blue. Appl. Clay Sci. 53, 553-560.

Foo, K.Y., Hameed, B.H., 2012. A rapid regeneration of methylene blue dye-loaded activated carbons with microwave heating, J. Anal. Appl. Pyrol. 98, 123-128.

Fournier, F., Viguerie, L., Balme, S., Janot, J-M., Walter, P., Jaber, M. 2016. Physicochemical characterization of lake pigments based on montmorillonite and carminic acid. Appl. Clay Sci. 130, 12-17.

Freundlich, H. M. F., 1906. Adsorption in solution. J. Phys. Chem. 57, 385-470.

Fu, Y.T.; Heinz, H., 2010. Structure and cleavage energy of surfactant-modified clay minerals: Influence of CEC, head group and chain length. Philos. Mag. 90, 24152424.

Guillermin, D., Debroise, T., Trigueiro, P., Viguerie, L., Rigaud, B., Morlet-Savary, F., Balme, S., Tielens, F., Michot, L., Lalevee, J., Walter, P., Jaber, M., 2018. New pigments based on carminic acid and smectites: A molecular investigation. Dyes and Pigments. 159, 384-394.

Gulicovski, J.J., Ĉerović , L.S.; Milonjić , S.K. Point of zero charge and isoelectric point of alumina, 2008. Mater. Manuf. Process. 23, 615-619.

Gupta, V.K., Suhas., 2009. Application of low-cost adsorbents for dye removal - a review. J. Environ. Manage. 90, 2313-2342.

Hassane, A., Khataee, A., Karaca, S., 2015. Photacatalytic degradation of ciprofloxacin by synthesized $\mathrm{TiO}_{2}$ nanoparticles on motmorillonite: Effect operation parameters and artificial neuralof network medeling. J. Mol. Catal. A: Chem. 409, 149-161. 
Heinz, H., Koerner, H., Anderson, K.L., Vaia, R.A., Farmer, B.L., 2005. Force field for micatype silicates and dynamics of octadecylammonium chains grafted to montmorillonite. Chem. Mater. 17, 5658-5669.

Heinz, H., Vaia, R.A., Krishnamoorti, R., Farmer, B.L., 2007. Self-assembly of alkylammonium chains on montmorillonite: effect of chain length, headgroup structure, and cation exchange capacity. Chem. Mater. 19, 59-68.

Ho, Y.S., Mckay, G., 1999. Pseudo-second order model for sorption processes. Process Biochem. 34, 5, 451-465.

Huang, Y., Li, S., Lin, H., Chen, J., 2014. Fabrication and characterization of mesoporous activated carbon from Lemna minor using one-step $\mathrm{H}_{3} \mathrm{PO}_{4}$ activation for $\mathrm{Pb}$ (II) removal. Appl. Surf. Sci. 317, 422-431.

Iftekhar, S., Ramasamy, D.L., Srivastava, V., Asif, M.B., Sillanpää, M., 2018. Understanding the factors affecting the adsorption of Lanthanum using different adsorbents: A critical review. Chemosphere, 204, 413-430.

Isah, U.A., Abdulraheem, G., Bala, S., Muhammad, S., Abdullahi, M., 2015. Kinetics, equilibrium and thermodynamics studies of C.I. Reactive Blue 19 dye adsorption on coconut shell based activated carbon. Int. Biodeterior. Biodegrad. 102, 265 - 273.

Jaber, M., Georgelin, T., Bazzi, H., Costa-Torro, F., Lambert, J-F., Bolbach, G., Clodic, G., 2014. Selectivities in adsorption and peptidic condensation in the (arginine and glutamic acid)/montmorillonite clay system, J. Phys. Chem. C 118, 25447-25455.

Janaki, V., Vijayaraghavan, K., Ramasamy, A., Lee, K., Oh, B., Kamala-Kannan, S., 2012. Competitive adsorption of Reactive Orange 16 and Reactive Brilliant Blue R on polyaniline/bacterial extracellular polysaccharides composite-A novel ecofriendly polymer. J. Hazard. Mater. 241-242, 110-117. 
Kar, S.; Kaur, T.; Thirugnanam, A., 20016. Microwave-assisted synthesis of porous chitosan-modified montmorillonite-hydroxyapatite composite scaffolds. Int. J. Biol. Macromol. 82, 628-636.

Kang, K., KIM, H., Lim, K., 2001. Effect of temperature on critical micelle concentration and thermodynamic potentials of micellization of anionic ammonium dodecyl sulfate and cationic octadecyl trimethyl ammonium chloride. Colloids Surf. A: Physicochem. Eng. Asp. 189, 113-121.

Kausar, A., Iqbal, M., Javed, A., Aftab, K., Nazli, Z., Bhatti, H., Nouren, S., 2018. Dyes adsorption using clay and modified clay: A review. J. Mol. Liq. 256, 395-407.

Khan, M.A., Alam, M.M., Naushad, M., Alothman, Z.A., Kumar, M., Ahamd, T., 2015. Sol-gel assisted synthesis of porous nano-crystalline CoFe2O4 composite and its application in the removal of brilliant blue-R from aqueous phase: An ecofriendly and economical approach, Chem. Eng. J. 279, 416-424.

Lagaly, G., Weiss, A., 1970. Arrangement and orientation of cationic tensides on silicate surfaces. 2. Paraffin-like structures in alkylammonium layer silicates with a high layer charge (mica). Koll. Z. Z. Polym. 237, 364-368.

Lam, S.S., Liew, R.K., Jusoh, A., Chong, C.T., Ani, F.N., Chase, H.A. 2016. Progress in waste oil to sustainable energy, with emphasis on pyrolysis techniques, Renew. Sust. Energ. Rev. 53, 741-753.

Lagaly, G., Weiss, A., 1971. Arrangement and orientation of cationic tensides on silicate surfaces. 4. Arrangement of alkylammonium ions in low-charged silicates in films. Koll. Z. Z. Polym. 243, 48-55.

Lagergren, S., Svenska, B.K., 1898. On the theory of so-called adsorption of materials. R. Swed. Acad. Sci. Doc. Band. 24, 1-13. 
Langmuir, I., 1916. The Constitution and fundamental properties of solids and liquids. I. Solids. J. Am. Chem. Soc. 38, 2221-2295.

Lazorenko, G., Kasprzhitskii, A., Yavna, V., 2018. Synthesis and structural characterization of betaine- and imidazoline-based organoclays. Chem. Phys. Lett. $692,264-270$.

Lepoitevin, M., Jaber, M., Guégan, R., Janot, J., Dejardin, P., Henn, F., Balme, S., 2014. BSA and lysozyme adsorption on homoionic montmorillonite: Influence of the interlayer cation. Appl. Clay Sci. 95, 396-402.

Liew, R.K., Nam, W.L., Chong, M.Y., Phang, X.Y., Su, M.H., Yek, P.N.Y., Ma, N.L., Cheng, C.K., Chong, C.T., Lam, S.S., 2018. Oil palm waste: An abundant and promising feedstock for microwave pyrolysis conversion into good quality biochar with potential multi-applications. Process Saf. Environ. 115, 57-69.

Lin-Vien, D., Colthup, N.B., Fateley, W.G., Grasselli, J.G., 1991. The handbook of infrared and Raman characteristic frequencies of organic molecules. Academic Press, London. 1-306.

Liu W, et al. 2012. Kinetics and thermodynamics characteristics of cationic yellow X-GL adsorption on attapulgite/rice hull-based activated carbon nanocomposites. Environ. Prog. Sust. Energ. 32(3), 655-62.

Ma, J., Cui,B., Dai, J., Li, D., 2011. Mechanism of adsorption of anionic dye from aqueous solutions onto organobentonite. J. Hazard. Mater. 186, 1758-1765.

Ma, L., Zhu, J., He, H., Xi, Y., Zhu, R., Tao, Q., Liu, D., 2015. Thermal analysis evidence for the location of zwitterionic surfactant on clay minerals. Appl. Clay Sci. $112-113,62-67$.

Mackenzie, R.C.J., 1951. A micromethod for determination of cation-exchange capacity of clay. J. Coll. Sci. 6, 219-222. 
Madejová, J., Bujdák, M., Komadel, P., 1998. Comparative FT-IR study of structural modifications during acid treatment of dioctahedral smectites and hectorite. Spectrochim. Act. A. 54, 1397-1406.

Makhoukhi, B., Djab, M., Didi, A.M., 2015. Adsorption of Telon dyes onto bisimidazolium modified bentonite in aqueous solutions. J. Environ. Chem. Eng. 3, 1384-1392.

Malakootian, M., Mansoorian, H.J., Hosseini, A., Khanjani, N., 2015. Evaluating the efficacy of alumina/carbon nanotube hybrid adsorbents in removing Azo Reactive Red 198 and Blue 19 dyes from aqueous solutions. Process Saf. Environ. 96, 125137.

Martinez-Costa, J., Leyva-Ramos, R., 2017. Effect of surfactant loading and type upon the sorption capacity of organobentonite towards pyrogallol. Colloid. Surface. A. $520,676-685$.

McCafferty, E., 2010. Relationship between the isoelectric point (pHpzc) and the potential of zero charge (Epzc) for passive metals. Electrochim. Acta, 55(5), 16301637.

Mellott, J.M., Hayes, W.A., Schwartz, D.K., 2004. Kinetics of Octadecyltrimethylammonium Bromide Self-Assembled Monolayer Growth at Mica from an Aqueous Solution. Langmuir 20, 2341-2348.

Menéndez, J.A., Illán-Gómez, M.J., y León, C.A.L., Radovic, L.R., 1995. On the difference between the isoelectric point and the point of zero charge of carbons. Carbon, 33(11), 1655-1657.

Mishra, A.; Mehta, A.; Sharma, M.; Basu, S., 2017. Enhanced heterogeneous photodegradation of VOC and dye using microwave synthesized TiO2/Clay 
nanocomposites: A comparison study of different type of clays. J. Alloy Compd. $694,574-580$.

Mizutani, T., Takano, T., Ogoshi, H., 1995. Selectivity of adsorption of organic ammonium ions onto smectite clays. Langmuir 11, 880-884.

Moslemizadeh, A., Aghdam, K.S., Shahbazi, K., Aghdam, K.H., 2016. Alboghobeish, F. Assessment of swelling inhibitive effect of CTAB adsorption on montmorillonite in aqueous phase. Appl. Clay Sci. 127-128, 111-122.

Ngulube, T., Gumbo, J.R., Masindi, V., Maity, A., 2017. An update on synthetic dyes adsorption onto clay based minerals: A state-of-art review. J. Environ. Manage. 191, $35-57$.

Ouellet-Plamondon, C., Stasiak, J., Al-Tabbaa, A., 2014. The effect of cationic, nonionic and amphiphilic surfactants on the intercalation of bentonite. Colloid. Surface. A. $444,330-337$.

Özcan, A., Ömeroğlu, Ç., Erdoğan, Y., Özcan, A., 2007. Modification of bentonite with a cationic surfactant: An adsorption study of textile dye Reactive Blue 19. J. Hazard. Mater. 140, 173-179.

Paiva, L.B., Morales, A.R., Díaz, F.R.V., 2008. Organoclays: Properties, preparation and applications. Appl. Clays Sci. 42, 8-24.

Park, C.W., Kim, B.H., Yang, H., Seo, B., Moon, J., Lee, K., 2017 Removal of cesium ions from clays by cationic surfactant intercalation. Chemosphere. 168, 1068-1074.

Park, Y., Ayoko, G., Frost, R., 2011. Characterisation of organoclays and adsorption of p-nitrophenol: Environmental application. J. Colloid Interf. Sci. 360, 440-456.

Pereira, F.A.R., Sousa, K.S., Cavalcanti, G.R.S., França, D.B., Queiroga, L.N.F.; Santos, I.M.G.; Fonseca, M,G.; Jaber, M., 2017. Green biosorbents based on 
chitosan-montmorillonite beads for anionic dye removal. J. Environ. Chem. Eng. 5, $3309-3318$

Petit, S.E., Madejov, J., 2013. Fourier transform infrared spectroscopy. In: Bergaya F, Theng, BKG, Lagaly G (eds) Handbook of clay science. Elsevier, Oxford, pp. 137170.

Rehman, F., Volpe, P.L.O., Airoldi, C., 2014. Free amino and imino-bridged centres attached to organic chains bonded to structurally ordered silica for dye removal from aqueous solution. J. Environ. Manage. 133, 135-143.

Ren, H., Tian, S., Zhu, M., Zhao, Y., Li, K., Ma, Q., Ding, S., Gao, J., Miao, Z., 2018. Modification of montmorillonite by Gemini surfactants with different chain lengths and its adsorption behavior for methyl orange. Appl. Clay Sci. 151, 29-36.

Sahin, O.; Kaya, M.; Saka, C., 2015. Plasma-surface modification on bentonite clay to improve the performance of adsorption of methylene blue. Appl. Clay Sci. 116-117, 46-53.

Sahnoun, S., Boutahala, M., Tiar, C., Kahoul, A., 2018. Adsorption of tartrazine from an aqueous solution by octadecyltrimethylammonium bromide-modified bentonite: Kinetics and isotherm modeling. C. R. Chim. 21, 391-398.

Salehi, S., Daraei, P., Shamsabadi, A.A., 2016. A review on chitosan-based adsorptive membranes. Carbohyd. Polym., 152, 419-432.

Santos, A., Viante, M., Pochapski, D., Downs, A., Almeida, C., 2018. Enhanced removal of p-nitrophenol from aqueous media by montmorillonite clay modified with a cationic surfactant. J. Hazard. Mater. 355, 136-144.

Sathishkumar, P., Arulkumar, M., Palvannan, T., 2012. Utilization of agro-industrial waste Jatropha curcas pods as an activated carbon for the adsorption of reactive dye Remazol Brilliant Blue R (RBBR). J. Clean. Prod. 22, 67-75. 
Schampera, B., Tunega, D., Šolc, R., Woche, S.K., Mikutta, R., Wirth, R., Dultz, S., Guggenberger, G., 2016. External surface structure of organoclays analyzed by transmission electron microscopy and X-ray photoelectron spectroscopy in combination with molecular dynamics simulations. J. Colloid Interf. Sci. 478, 188200.

Silva, M.M.F., Oliveira, M., Avelino, M.C., Fonseca, M.G. , Almeida, R.K.S., Filho, E.C.S., 2012. Adsorption of an industrial anionic dye by modified-KSFmontmorillonite: Evaluation of the kinetic, thermodynamic and equilibrium data. Chem. Eng. J. 203, 259-268.

Silva, T.L., Ronix, A., Pezoti, O., Souza, L.S., Leandro, P.K.T., Bedin, K.C., Beltrame, K.K., Cazetta, A.L., Almeida, V.C., 2016. Mesoporous activated carbon from industrial laundry sewage sludge: Adsorption studies of reactive dye Remazol Brilliant Blue R. Chem. Eng. J. 303, 467-476.

Sun, K., Shi, Y., Chen, H., Wang, X., Li, Z., 2017. Extending surfactant-modified 2:1 clay minerals for the uptake and removal of diclofenac from water. J. Hazard. Mater. $323,567-574$

Sun, Z., Park, Y., Zheng, S., Ayoko, G., Frost, R., 2013. Thermal stability and hot-stage Raman spectroscopic study of Ca-montmorillonite modified with different surfactants: A comparative study. Thermochim. Acta. 569, 151-160.

Swartzen-Allen, S., Matijevic, E., 1974. Surface and colloid chemistry of clays. Chem. Rev. 74(3), 385-400.

Taleb, K., Pillin, I., Grohens, Y., Saidi-Besbes, S., 2018. Gemini surfactant modified clays: Effect of surfactant loading and spacer length. Appl. Clay Sci. 161, 48-56. 
Tangaraj, V., Janot, J., Jaber, M., Bechelany, M., Balme, S., 2017. Adsorption and photophysical properties of fluorescent dyes over montmorillonite and saponite modified by surfactant. Chemosphere. 184, 1355-1361.

Temkin, M.J., Pyzhev, V., 1940. Recent modifications to Langmuir Isotherms. Acta Physiochim. 12, 217-222.

Teppen, B., Aggarwal, V., 2007. Thermodynamics of organic cation exchange selectivity in smectites. Clay Clay Miner. 55, 119-130.

Thue, P., Sophia, A., Lima, E., Wamba, A., Alencar, W., Reis, G., Rodembusch, F., Dias, S., 2018. Synthesis and characterization of a novel organic-inorganic hybrid clay adsorbent for the removal of acid red 1 and acid green 25 from aqueous solutions. J. Clean. Prod. 171, 30-44.

Torgut, G.; Tanyol, M.; Biryan, F.; Pihtili, G.; Demirelli, K., 2017. Application of response surface methodology for optimization of Remazol Brilliant Blue R removal onto a novel polymeric adsorbent. J. Taiwan Inst. Chem. E. 80, 406-414.

Trigueiro, P., Rodrigues, F., Rigaud, B., Balme, S., Janot, J., Santos, I.M.G., Fonseca, M.G., Osajima, J., Walter, P., Jaber, M., 2018. When anthraquinone dyes meet pillared montmorillonite: Stability or fading upon exposure to light? Dyes and Pigments. 159, 384-394.

Tunç, S., Duman, O., Kanci, B., 2012. Rheological measurements of Na-bentonite and sepiolite particles in the presence of tetradecyltrimethylammonium bromide, sodium tetradecyl sulfonate and Brij 30 surfactants. Colloid. Surface. A. 398, 37-47.

Unuabonah, E.I., Adebowale, K.O., Dawodu, F.A., 2008. Equilibrium, kinetic and sorber design studies on the adsorption of aniline blue dye by sodium tetraboratemodified kaolinite clay adsorbent. J. Hazard. Mater. 157, 397-409. 
Xi, Y., Ding, Z., He, H., Frost, R., 2005. Infrared spectroscopy of organoclays synthesized with the surfactant octadecyltrimethylammonium bromide. Spectrochim. Acta A. 61, 515-525.

Yan, L., Qin, L., Yu, H., Li, S., Shan, R., Du, B., 2015. Adsorption of acid dyes from aqueous solution by CTMAB modified bentonite: Kinetic and isotherm modeling. J. Mol. Liq. 211, 1074-1081.

Yagub, M.T., Sen, T.K., Afroze, S., Ang, H.M., 2014. Dye and its removal from aqueous solution by adsorption: A review. Adv. Colloid Interfac. 209, 172-184.

Wang, G., Wang, S., Sun, Z., Zheng, S., Xi, Y., 2017. Structures of nonionic surfactant modified montmorillonites and their enhanced adsorption capacities towards a cationic organic dye. Appl. Clay Sci. 148, 1-10.

Zhang A, Mu B, Luo Z, Wang A., 2017. Dyes and Pigments Bright blue halloysite / $\mathrm{CoAl}_{2} \mathrm{O}_{4}$ hybrid pigments : Preparation , characterization and application in waterbased painting. Dyes and Pigments, 139, 473-481.

Zhang, B., Dongb, Z., Sunb, D., Wua, T., Lia, Y., 2016. Enhanced adsorption capacity of dyes by surfactant-modified layered double hydroxides from aqueous solution. J. Ind. Eng. Chem. 49, 208-218.

Zhu, J., Shen, W., Ma, Y., Ma, L., Zhou, Q., Yuan, P., Liu, D., He, H., 2012. The influence of alkyl chain length on surfactant distribution within organomontmorillonites and their thermal stability. J. Therm. Anal. Calorim. 109, 301-309.

Zhu, R., Chen, Q., Zhou, Q., Xi, Y., Zhu, J., He, H., 2015. Adsorbents based on montmorillonite for contaminant removal from water: A review. Appl. Clay Sci. 123, 239-258. 


\section{Supplementary material}

Figure SM1. Molecular structure of the dyes a) Remazol yellow GR, b) Remazol red RB and c) Remazol blue RN.

Figure SM2. SEM for (a) pristine and organobentonites (b) Bent-C14-100\%, (c), BentC16-100\%, (d) Bent-C18-100\%, (e) Bent-C14-200\%, (f) Bent-C16-200\% and (g) BentC18-200\%.

Figure SM3. Effect of the dosage of the adsorbent on the adsorption of Remazol blue RN by (a) pristine and organobentonites obtained with (i) $100 \%$ and (ii) $200 \%$ of the CEC using the surfactants (b) C14, (c) C16 and (d) C18 at $303 \mathrm{~K}$. Experimental conditions: 25 to $100 \mathrm{mg}$ of solid, $20 \mathrm{~mL}$ of the $500 \mathrm{mg}$ g-1 dye solution, contact time of $24 \mathrm{~h}, \mathrm{pH} 2.0$ at $303 \mathrm{~K}$.

Figure SM4. Fitting of the adsorption data of Remazol blue RN on organobentonites (a) Bent-C14, (b) Bent-C16 and (c) Bent-C18 prepared with (i) 100 and (ii) 200\% of the CEC for pseudo-first order; (iii) 100 and (iv) 200\% of the CEC for pseudo-second order and (v) 100 and (vi) $200 \%$ of the CEC for Elovich models.

Figure SM5. Fitting of the adsorption data of Remazol blue RN on organobentonites (a) Bent-C14, (b) Bent-C16 and (c) Bent-C18 prepared with (i) 100 and (ii) $200 \%$ of the CEC for Langmuir; (iii) 100 and (iv) 200\% of the CEC for Freundlich and (v) 100 and (vi) $200 \%$ of the CEC for Temkin models. 
Figure SM6. i) XRD patterns; ii) UV-VIS solid stated spectra for Bent-C14-200\% a) before and b) after dye removal and iii) infrared spectra for a) Bent-C14-200\%, b) Remazol blue dye and c) Bent-C14-200\% after dye removal.

Figure SM7. Proposed mechanism for the interaction between the dye and the organobentonites on the external and interlayer regions.

Figure SM8. UV-VIS absorption spectra of the synthetic dye effluent before and after adsorption for pure bentonite and hybrids prepared with (i) $100 \%$ and (ii) $200 \%$ of the CEC in a pH of 2.0 and (iii) $100 \%$ and (iv) $200 \%$ of the $\mathrm{CEC}$ in a $\mathrm{pH}$ of 6.4 for (a) initial dye effluent solution and the solutions after adsorption using solids modified with (b) Bent, (c) C14, (d) C16 and (e) C18. Experimental conditions: 3 h, 298 K, 75 mg of solid and $20 \mathrm{~mL}$ of effluent solution.

Figure SM9. Results for the removal of the dyes at $\mathrm{pH}$ value of 2.0 in a synthetic effluent by monitoring using UV-Vis spectrometry at the maximum absorptions of 412 , 540 and $609 \mathrm{~nm}$ for organobentonite.

Table SM1. Values of the basal spacing for organobentonites prepared with the surfactants C14, C16 and C18 for solids obtained by conventional heating accordingly to the literature.

Table SM2. Data of mass losses and temperature (T) obtained from thermogravimetry (TG/DTG) for the pristine and organo bentonites.

Table SM3. Adsorption capacity and time for remazol blue RN dye by using different adsorbents. $\mathrm{R}^{2}$ is the correlation coefficient obtained by fitting experimental data to pseudo-second order model. 
